\title{
Article \\ The Effect of the Decorative Surface Layer on the Dynamic Properties of a Symmetric Concrete Slab
}

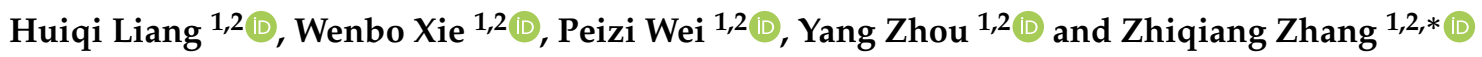 \\ 1 Key Laboratory of Concrete and Prestressed Concrete Structure, Ministry of Education, Southeast University, \\ Nanjing 210096, China; 220181081@seu.edu.cn (H.L.); xie123wenbo@seu.edu.cn (W.X.); \\ 230198492@seu.edu.cn (P.W.); 220141041@seu.edu.cn (Y.Z.) \\ 2 School of Civil Engineering, Southeast University, Nanjing 210096, China \\ * Correspondence: 230208105@seu.edu.cn
}

check for updates

Citation: Liang, H.; Xie, W.; Wei, P.; Zhou, Y; Zhang Z. The Effect of the Decorative Surface Layer on the Dynamic Properties of a Symmetric Concrete Slab. Symmetry 2021, 13, 1174. https://doi.org/10.3390/ sym 13071174

Academic Editor: Jan Awrejcewicz

Received: 26 May 2021

Accepted: 26 June 2021

Published: 29 June 2021

Publisher's Note: MDPI stays neutral with regard to jurisdictional claims in published maps and institutional affiliations.

Copyright: (c) 2021 by the authors. Licensee MDPI, Basel, Switzerland. This article is an open access article distributed under the terms and conditions of the Creative Commons Attribution (CC BY) license (https:// creativecommons.org/licenses/by/ $4.0 /)$.

\begin{abstract}
In the past few years, the immense advances in building materials and construction techniques have inspired the development of large span, light, and flexible structures with low damping. The low frequency and low damping properties of the mentioned structures result in the problem of serviceability caused by human-induced vibrations. An evaluation of the serviceability of a structure requires obtaining the modes and natural frequencies of the structure via the finite element method (FEM). In the design stage, the structural model considers the contribution of involved elements made to the stiffness of the whole structure, such as beams, slabs, and columns, while the decorative surface layer above the floor is often regarded as an additional mass, regardless of its contribution to the stiffness of the floor slab. In this study, the dynamic properties of a symmetric concrete slab were tested with an ambient excitation method to obtain the dynamic properties of the original empty structure and the structure decorated with a tiled surface, a marble surface, and a terrazzo surface, respectively. The results show that the first-order natural frequencies of floor slabs decorated with tile, marble, and terrazzo finishes are decreased compared to the original empty structure, while the second- and third-order ones are increased, which indicates that it is improper to treat decorative finishes purely as an additional mass. By equating the decorative layer to a certain thickness of additional concrete layer in the finite element model, it is found that, if the decorative surface layer is equated to a $29-31 \mathrm{~mm}$ thick additional layer and the weight of the equivalent additional layer is the same as that of the actual decorative surface, the simulation results will be in good agreement with the measured results. Moreover, the test results indicate that the first-order shape function of the structure is symmetric and its second- and third-order shape functions are antisymmetric, which is consistent with the results of simulations under FEM method. This provides a basis for designers to evaluate the contribution of the additional layers in structural serviceability analysis.
\end{abstract}

Keywords: decorative surfaces; vibration testing; dynamic analysis; symmetric shape function; vibration serviceability

\section{Introduction}

In recent years, with an increasing application of lightweight and high-strength materials, immense advances in structural analysis, design techniques, and a rapid development of construction technology, the developments of lightweight floor slab and large-span floor cover systems have gained momentum [1-5]. Due to the low vertical natural frequency and the lower mass and damping of this floor cover system, many concerns have been raised when the frequencies of daily activities of people on the structure (e.g., walking, jumping, and running) are close to the vertical frequency of the structure, which can potentially induce structural resonance and thus vibration comfort problems [6-16].

It is substantial to obtain the accurate vertical frequencies of the slab if an analysis of the dynamic properties of the slab is required to evaluate the serviceability of a floor 
slab. Unlike a bare floor slab, a floor slab in its serviceable state may have a variety of non-structural components that can modify the dynamic properties of the original floor slab [17-21]. Another issue worth noting is that, when the comfort evaluation of the floor slab is considered, the occupancy of the human body also has a non-negligible effect on the dynamic properties of the structure, which is a hot topic of research in the field of human-structure interaction. The retention of the human body not only decreases the frequency of the structure [22,23] (the human body regarded as an additional mass) but also increases the damping of the human-structure coupled system of human-structure interactions [24-28]. Eills and Ji observed the production of a new mode shape when the dynamic properties of Twickenham Stadium were tested during the crowd occupancy [23]. Litter and JD found that the test results of a grandstand structure showed that the vertical and horizontal modes of the structure can be altered together due to the occupancy of the crowd $[29,30]$. Setareh and Mehdi conducted a field test and numerical analysis of a long cantilevered office building structure before and after the completion of the raised floor and nonstructural elements. The comparison showed that the raised flooring and nonstructural elements acted mainly as added mass and did not contribute to the structure stiffness, and there was no added damping due to the installation of raised flooring and nonstructural elements as well [31]. Regarding full-height non-structural partitions, Middleton and Pavic performed a modal test on a structure in various stages of construction and proved that the partitions can increase the overall frequency and local stiffness of the structure, with the damping of structure increasing as well [32]. Devin et al. investigated the potential beneficial effects of nonstructural partitions on the vibration serviceability of a floor due to walking excitation through a finite-element model and found that the addition of nonstructural partitions successfully reduced floor acceleration and helped the floor to satisfy the vibration serviceability criterion for office floors [33]. Andersen et al. focused on wooden floors built as an assembly of particleboard and timber joists with a finite element method and concluded that non-structural mass must be taken into account in a dynamic assessment of a wooden floor, which also has a significant effect on its modal properties [34].

It is worth noting that a majority of studies have focused on the effect of fixed components (full-height non-structural partitions) and mobile components (furniture) on the dynamic properties of the floor slab, but very few studies on decorative finishes have been conducted. Based on the knowledge of the structural dynamics, the first-order natural frequency of the structure can be estimated through the equation: $f_{s}=\frac{1}{2 \pi} \sqrt{\frac{k}{m}}$. Clearly, if one only considers the mass of the decorative surface layer, the natural frequencies of the structure will definitely decrease. However, according to the tests and experimental results presented by Falati, the frequencies of the slab are not decreasing significantly as expected [35]. The reason might be that the stiffness contribution of the additive surface is not negligible when the dynamic properties of the structure are calculated. Compared with partitions and furniture, which are non-permanent components, decorative surfaces, as a permanent non-structural component, have a non-negligible impact on the vibration characteristics of the floor slab. Falati investigated the dynamic properties of non-structural elements on concrete slabs by casting two separate $25 \mathrm{~mm}$ thick layers of concrete with viscoelastic material on the surface of the bare slab [35]. The test results show that the additional viscoelastic screed layers increased the natural frequencies and damping ratios of the original structure, and Falati concluded that this layer should be considered as a structural layer instead. Except for the additional surface layer, the change of the natural frequencies of the slab can be related to other boundary conditions, that is, the shape of the building, the dimensions of the structural elements, and the constitutive elements of the slab. In the investigation of the seismic fragility and structural behaviour of RC buildings, the in-plane deformation of the floor slab is often neglected, which is related to the shape of the buildings and presence of stiff vertical elements, making the vulnerability estimation results of the building not conservative [36,37]. 
In the design process of the structure, the contributions of the structural members such as beams, plates, and columns to the rigidity of the overall structure are well considered. The decorative surface layer such as the marble surface or the tile surface is typically regarded as the additional mass to the structure by designers. Few studies have been carried out to examine the impact of the existence of decorative finishes on the dynamic properties of the concrete floor slabs, which are important for the floor slab design when the human-induced vibration has to be assessed. Owing to the semi-rigidity of the connection between the decorative surface and the bare structural surface, it is essential to equalize the decorative surface to a certain thickness of pure concrete surface for design feasibility. In this study, we obtained the dynamic properties of a full-scale concrete floor slab without decoration and a slab decorated with tiles, marble, and terrazzo in four different states by modal tests, and the experimental data were compared with the results obtained from the finite element method (FEM). We concluded that the decorative surface can be equated to a certain thickness of concrete layer, which provides an efficient and convenient method for the design of slab comfort.

The structure of this paper is as follows. In Section 2, the test setup and platform for the identification of modal properties of the floor slab are presented. The identification method and details and procedures of the test are also introduced in this section. In Section 4, the identification results of the concrete floor slab in three decorative states are presented. A comparison of the experimental results with the finite element results is shown in Section 4. Conclusions are drawn in Section 5.

\section{Design of the Experiment}

To investigate the effect of decorative surfaces on the dynamic properties of the structure, a large span four-end simply supported concrete slab was assumed as the study object. Three types of materials, tile, marble, and terrazzo, were used to prepare the decorative surfaces of the slab.

\subsection{Specimen Design}

The concrete slab has a dimension of $3000 \mathrm{~mm} \times 6000 \mathrm{~mm}$, the edge beam has a dimension of $250 \mathrm{~mm} \times 400 \mathrm{~mm}$, and the intermediate beam has a dimension of $200 \mathrm{~mm} \times 250 \mathrm{~mm}$, as shown in Figure 1a. The concrete slab is supported at four corner points by four columns built of brick, all other boundary conditions being free (Figure 1d). The strength grade of concrete of cast-in-place beam and slab is C30, and the thickness of the concrete protection layer is $25 \mathrm{~mm}$. HRB400 grade hot rolled steel reinforcement with diameters of 14 and $20 \mathrm{~mm}$ were used for beam reinforcement. HRB400 grade hot rolled steel reinforcement with diameter of $8 \mathrm{~mm}$ was used for hoop reinforcement, and the spacing between hoops was set as $200 \mathrm{~mm}$. The slab is a single-reinforced member, and the reinforcement is HRB400 grade hot-rolled steel bars with a diameter of $8 \mathrm{~mm}$ and a spacing of $200 \mathrm{~mm}$. The plate is $120 \mathrm{~mm}$ thick, and the supports are made of bricks with a height of $1 \mathrm{~m}$. The slab was built in accordance with the requirements of Chinese structure design standard (GB 50010-2010) [38] and the building seismic design code (GB 50011-2010) [39]. The specimen size and reinforcement plan are shown in Figure 1, while Figure 2a shows photos of the maintenance process of the test platform.

In the tests, we adopted the approach to laying the three decorative finishes on the same concrete slab at different phases, rather than building four different slabs at the same time, that is, the reference slab, slab with ceramic tiles, slab with terrazzo, and slab with marble. We adopted this scheme for the following purposes.

- Casting only one slab saves material, reduces site occupation. and enables sustainability.

- $\quad$ By applying the surface layer on the same slab, the influence of uncontrollable factors on the dynamic properties of the original structural slab during the casting process is reduced. We expect the dynamic properties of the original structure to remain identical under different decorative surfacing conditions. 


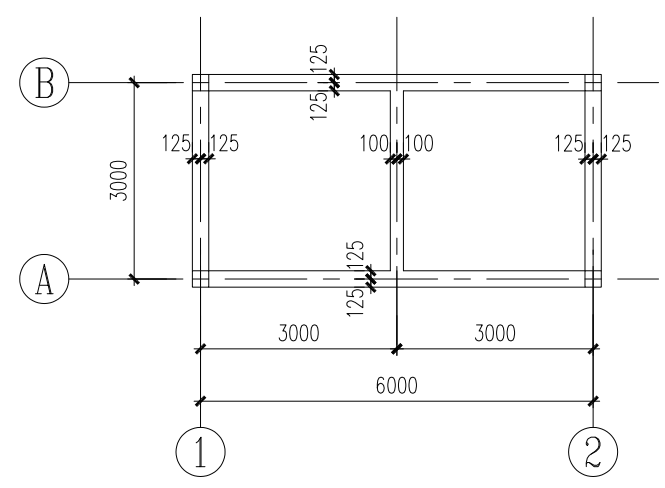

(a)

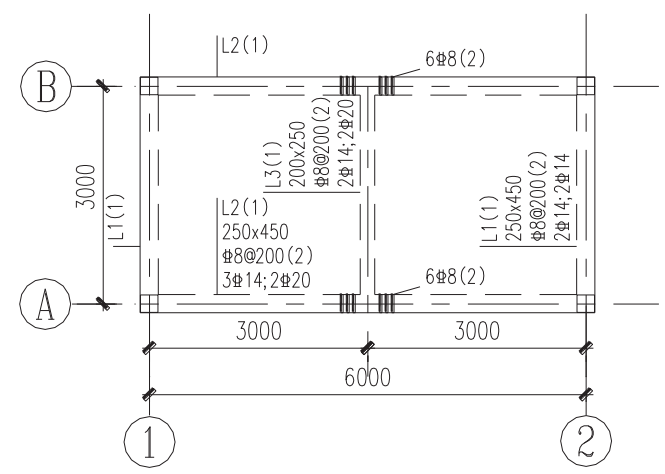

(c)

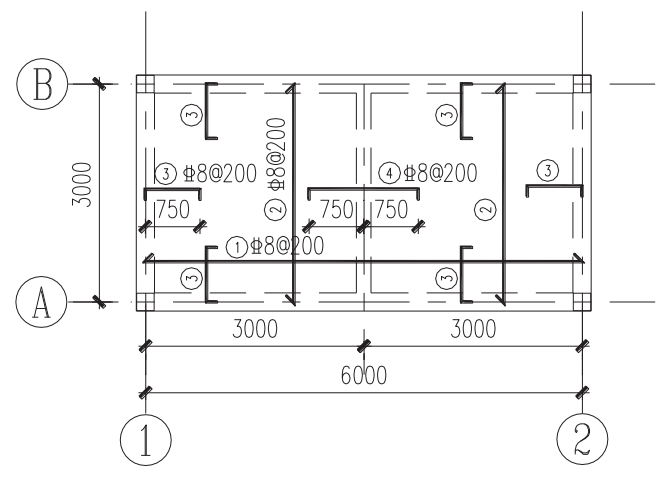

(b)

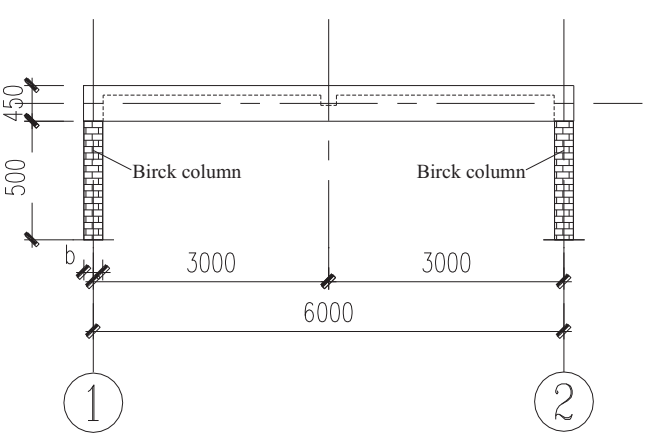

(d)

Figure 1. The layout of and reinforcements arrangement of the test platform: (a) layout of the plate; (b) arrangement of reinforcements in the floor slab; (c) arrangement of beam reinforcements; and (d) side view of the long side of the plate.

It is worth noting that the test results in Section 3 show that the dynamic properties of the original structure in three phases changed little after the surface layer is removed, which demonstrates the soundness of our solution to adopt the same slab for all three surface layers. Three common construction decorative materials, tile, marble, and terrazzo, were utilized to serve as the decorative surfaces. Preparations for the surface layers are as follows.

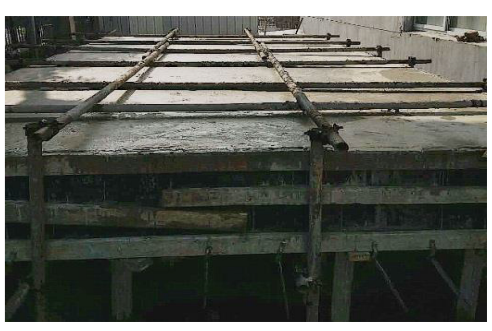

(a)

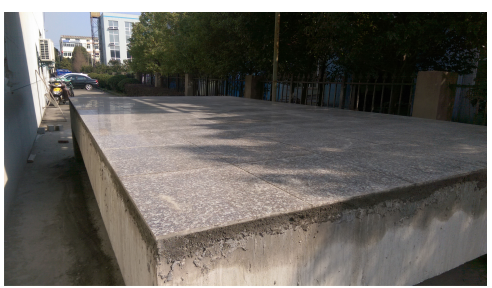

(c)

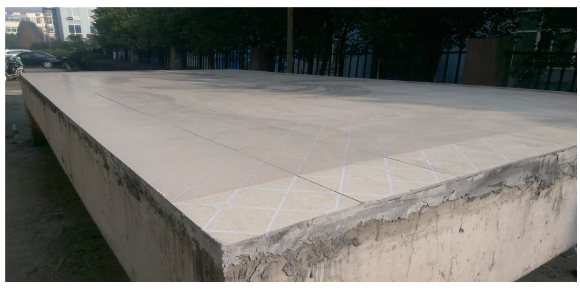

(b)

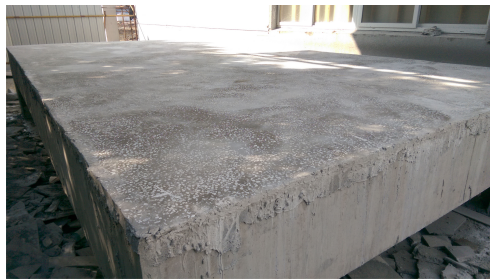

(d)

Figure 2. Test platform: (a) the maintenance of the test platform; (b) plate with ceramic tiles surface; (c) plate with marble surface; and (d) plate with terrazzo surface. 
Regarding the material of ceramic tile, the size of ceramic tile is $300 \times 300 \mathrm{~mm}$, the thickness is 7-8 mm, and the gap between each tile is filled with thin cement slurry. A 30 $\mathrm{mm}$ thick layer of cement mortar with a mix ratio of water to cement as 1:3 lies on top of the concrete slab. For the marble surface, the thickness was set as $15 \mathrm{~mm}$, with the cement slurry filling the gap. The mortar's thickness is the same as that of the ceramic tile, with a mix ratio of water to cement of 1:3 as well. In the case of terrazzo, the thickness is $30 \mathrm{~mm}$ with a mix ratio of water to white cement of $1: 2.5$, and the surface was waxed.

\subsection{Material Properties}

\subsubsection{Concrete Strength}

Concrete with a strength grade C30 was used in the construction of the slab. Three groups of cube specimens with a side length of $150 \mathrm{~mm}$ cured under the same conditions were taken to be tested, and the average value of compressive strength of concrete at 28 days of age was taken as the measured value of concrete cube compressive strength, in accordance with the Chinese code (GB/T 50081-2019) [40]. Table 1 lists the measured values of the compressive strength of the concrete cube.

Table 1. Measured material properties of concrete.

\begin{tabular}{cccc}
\hline \multirow{2}{*}{ Maintenance Conditions } & \multirow{2}{*}{ Strength Grade } & \multicolumn{2}{c}{ Compressive Strength/MPa } \\
\cline { 3 - 4 } & & Specimen Value & Representative Value \\
\hline \multirow{2}{*}{ Outdoors } & C30 & 31.4 & 31.87 \\
& & 32.3 & \\
\hline
\end{tabular}

\subsubsection{Ceramic Tiles, Marble and Terrazzo}

The ceramic tiles were made from $300 \mathrm{~mm} \times 300 \mathrm{~mm}$ glazed tiles which are commonly available in the building materials store. Before construction, 60 tiles were selected and a point on each of the four sides of each tile was chosen randomly for thickness measurement with a vernier caliper. Meanwhile, the mass of each piece was measured with an electronic scale and the average of the two items was tabulated, as shown in Table 2. The cement, sand, and water used in the construction process were quantitatively weighed and recorded, and then the areal density of the surface layer (including the tiles) was calculated to be $1.017 \mathrm{kN} / \mathrm{m}^{2}$, while the average thickness of the measured cement mortar surface layer was $0.038 \mathrm{~m}$. Regarding the marble slab, the thickness of the marble slab is $15 \mathrm{~mm}$, and the average values of their masses and thicknesses are shown in Table 2. For the material terrazzo, the terrazzo was poured together with a mixture of cement ( composite silicate cement PC 32.5R) and fine white stone granules, and then sprinkled with stone granules on the surface before leveling and manually smoothed after the surface had hardened to a certain extent. Once the structural dynamic properties of the structure with the terrazzo surface were tested, 10 points were selected on the surface and the thickness of the terrazzo surface was measured during the process of removing the surface layer. The average thickness data obtained from these 10 points are shown in Table 2. The areal density of the surface layer of the marble and terrazzo surface was calculated to be 1.155 and 0.968 $\mathrm{kN} / \mathrm{m}^{2}$, respectively; the average thickness of the measured cement mortar surface layer of the marble surface was $0.033 \mathrm{~m}$; and the thickness of the terrazzo surface was $0.0289 \mathrm{~m}$.

Table 2. Average thickness and mass of three types of decorative materials.

\begin{tabular}{ccc}
\hline \multirow{2}{*}{ Types of Material } & \multicolumn{2}{c}{ Measurement Items (Average Values) } \\
\cline { 2 - 3 } & Mass & Thickness \\
\hline Ceramic tile & $1.361 \mathrm{Kg}$ & $7.51 \mathrm{~mm}$ \\
Marble & $12.315 \mathrm{Kg}$ & $1.57 \mathrm{~mm}$ \\
Terrazzo & - & $2.89 \mathrm{~mm}$ \\
\hline
\end{tabular}




\subsection{Test Plan and Measurement Details \\ 2.3.1. Measuring Devices}

In the model test part, the Signal Acquisition and Analysis Systems (AZCRAS) developed by AnZheng Software Engineering Co were employed. It includes the AZ804-B conditioner, which can amplify and filter the signal, and the AZ308 acquisition box, which is used to collect the signal. The 941-B ultra-low vibration sensor is used to record the vibration response, and the pulse force hammer is utilized to generate impulse excitation. Details are outlined in Table 3 . The test devices are shown in Figure 3.

Table 3. Instruments for data acquisition and signal processing.

\begin{tabular}{ccc}
\hline Instruments & Quantity & Main Technical Specifications \\
\hline 941-B Ultra Low Frequency Piezoelectric Vibration Pickup & 1 & Passband 0.25 Hz to $80 \mathrm{~Hz}$ \\
AZ308 signal acquisition box & 1 & 8 channels \\
AZ804-B Conditioner & 1 & 8 channels \\
AZ_CRAS Dynamic Signal Test and Analysis System & 1 & Version 7.4 \\
Pulse force hammers & 1 & - \\
LK141-43 force sensor & 1 & Sensitivity 4.19 PC/N Range 100 kN \\
Sensor data connection cable & 2 & - \\
Coaxial Cable Data Cable & 3 & - \\
Computer & 1 & - \\
Power supply box & 1 & Voltage 220 V \\
\hline
\end{tabular}

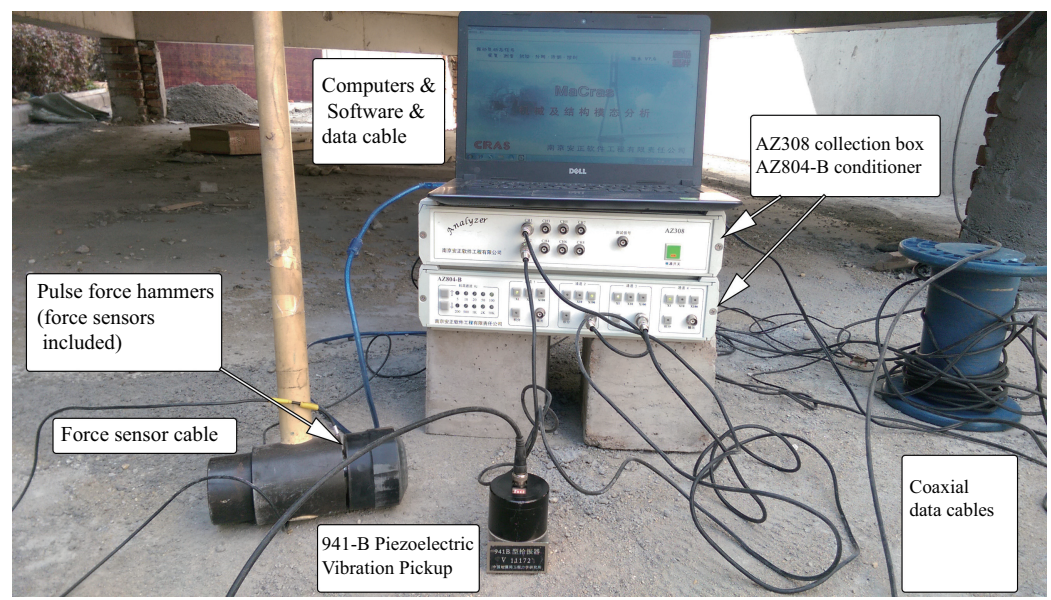

Figure 3. The layout of the main test devices.

\subsubsection{Experimental Scheme and Methods}

To investigate the impact of decorative finishes on the dynamic properties of the structure, the modal tests can be divided into six phases depending on the type of finish and the period time of construction. Details are provided below (Table 4).

- $\quad$ Phase I: The structure was maintained in a natural environment for 28 days after completion of the casting and is referred to the Original Structure A.

- $\quad$ Phase II: The surface of the Original Structure A was maintained in a natural environment for 7 days after the laying of a plain tile surface, and it is recorded as the tile structure.

- $\quad$ Phase III: The surface of the structure was cleaned after removing the tiles and mortar topping from the original structural surface, and it is denoted as Original Structure B.

- Phase IV: Terrazzo was topped on the surface of the Original Structure B. The surface was smoothly polished, maintained for 7 days, and marked as the terrazzo structure.

- Phase V: The terrazzo surface was removed from the Original Structure A and the surface was cleaned of debris and small pieces of mortar. The structure is denoted as Original Structure C. 
- $\quad$ Phase VI: The structure was marked as the marble structure after the marble topping was laid on the surface of the Original Structure $C$ and maintained in a natural environment for 7 days.

The modal dynamic tests were carried out on the structure at each of the six stages mentioned above. It is necessary to carry out the model test on the original structure in Phases III and V as the dynamic properties may change due to the possible structural damage and defects during the surfacing and smashing of the surface of the original structure. This test employs frequency domain analysis for the identification of modal parameters of the floor slab and adopts a single-point excitation, multi-point response (SIMO) test scheme. The test was conducted using a force hammer for impulse excitation and a rubber tip was attached to the striking end of the hammer. A 941-B piezoelectric acceleration sensor was employed to collect the vibration velocity at each measurement point on the test floor as the impulse excitation response of the structure, with the sensor using a medium velocity range of v.s. $/ \mathrm{m}$. In total, 35 measurement points were placed on the entire plate, as shown in Figure 4.

Table 4. Modal test results of Original Structures A-C.

\begin{tabular}{cccc}
\hline Test Structure & Document Number & Hammering Point & Test Number \\
\hline \multirow{5}{*}{ Original Structure A } & $\mathrm{A}$ & 7 & 1 \\
& $\mathrm{~B}$ & 7 & 2 \\
& $\mathrm{C}$ & 7 & 3 \\
& $\mathrm{D}$ & 9 & 4 \\
Tile structure & $\mathrm{E}$ & 9 & 5 \\
& $\mathrm{~F}$ & 7 & 6 \\
& $\mathrm{G}$ & 7 & 7 \\
\hline \multirow{3}{*}{ Original Structure } & $\mathrm{H}$ & 7 & 8 \\
& $\mathrm{I}$ & 7 & 9 \\
& $\mathrm{~J}$ & 7 & 10 \\
Terrazzo Structure & $\mathrm{K}$ & 7 & 11 \\
& $\mathrm{~L}$ & 7 & 12 \\
& $\mathrm{M}$ & 7 & 13 \\
Original Structure C & $\mathrm{N}$ & 7 & 14 \\
& $\mathrm{O}$ & 7 & 15 \\
& $\mathrm{P}$ & 7 & 16 \\
\hline \multirow{3}{*}{ Marble Structure } & $\mathrm{Q}$ & 7 & 17 \\
& $\mathrm{R}$ & 7 & 19 \\
\hline
\end{tabular}

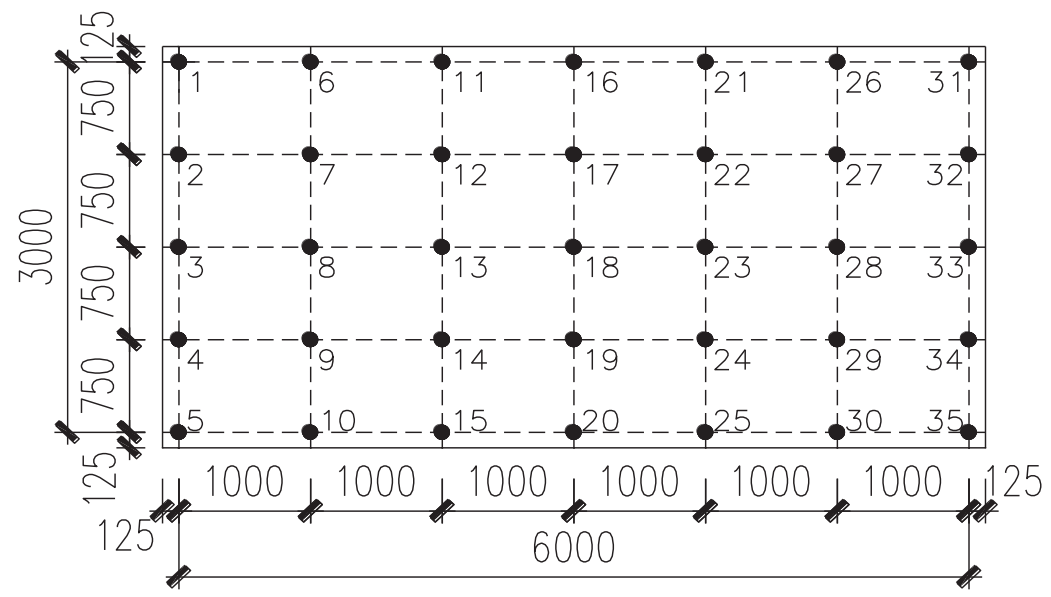

Figure 4. Layout of floor measurement points. 
Five vibration tests were carried out on the Original Structure A. In three tests, the pulsing hammer was struck at Point 7 and, in two tests, the pulsing hammer was struck at Point 9. Three vibration tests were carried out at the other five phases of the structure, with the impulse hammer striking at Point 7 in all three tests, to identify the first three orders of vertical modes of the test structure more accurately. As mentioned above, the AZ804-B 8 -channel dynamic data acquisition system was used for vibration signal acquisition. Two channels were used for mobile acquisition for this test: Channel 1 was used to measure the force output of the force hammer, while Channel 2 was used to measure the vibration response of the measurement point. The test was carried out with the knocking point fixed, but the response measurement points moved. As the response of the measured point is recorded with the same vibration sensor, amplifier, and filter, there is no inter-channel error that should be taken care of if signals are collected simultaneously with multiple channels. In the experimental process, 35 frequency response functions (FRF) were obtained.

\section{Analysis of Modal Test Results}

Through the modal testing of the floor slab, a series of sensor response signals of the sensor in the time domain under hammering excitation was obtained. Transforming the signal from the time domain into the frequency domain for spectral analysis, the modal parameter identification technique was applied to obtain the dynamic properties of the slab including the natural frequency and mode shape function through the frequency response function of each measurement point.

The modal parameters of the structure were analyzed using the SIMO modal analysis method as previously described. By initially estimating the modal frequency and marking the frequency corresponding to the peak value of the average curve of the frequency response function, the curve fitting was completed according to the modal theory and fitting methods, followed by the process of measurement direction and the constraint equations. From the theoretical analysis of the eigenvalue problem for linear vibration systems, any two eigenvectors should be orthogonal. We used the modal characteristics of the theoretical model to check for possible exceptional measurement conditions and retested these points until the conditions were satisfied.

\subsection{Modal Test Results of the Original Structure}

Using the method mentioned above, modal tests were conducted on Original Structures A-C. The velocity time history and velocity power spectrum curve of Point 18 of Test 2 during the modal test of the Original Structure A are shown in Figures 5 and 6.

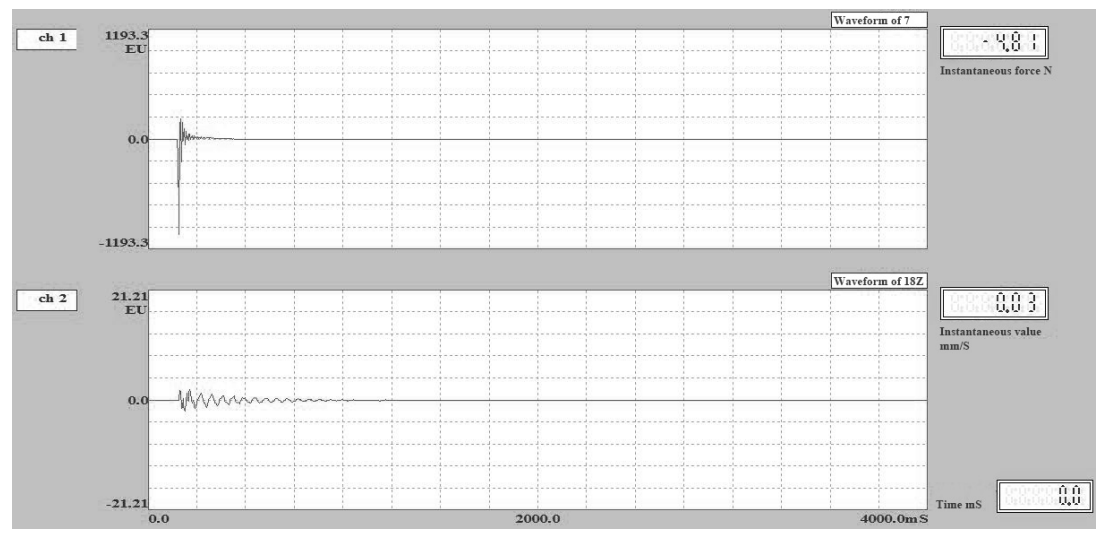

Figure 5. The velocity time curve of Measurement Point 18 in Test 2. 


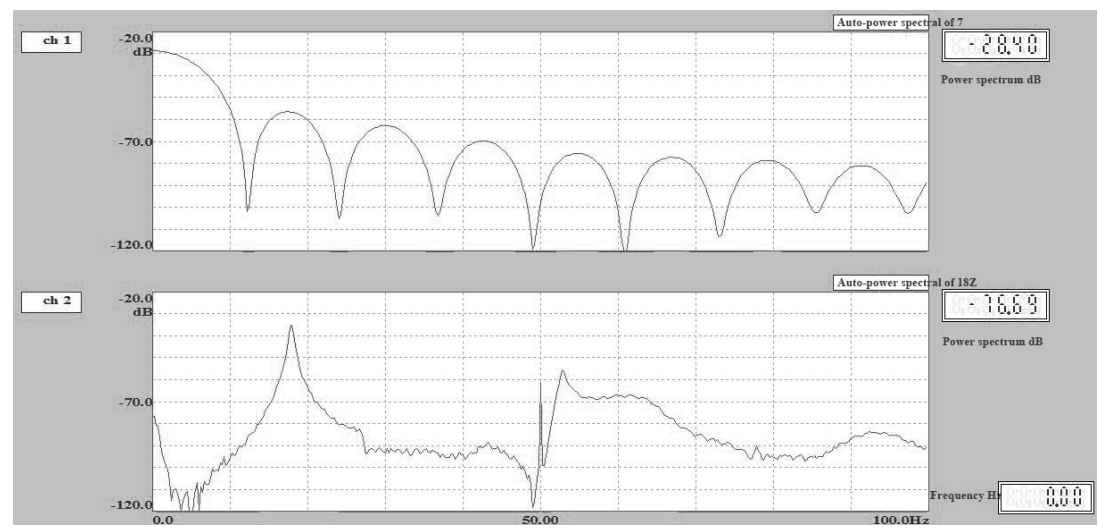

Figure 6. Velocity power spectrum curve of Point 18 in Test 2.

The natural frequency and shape functions of the first three modes of the Original Structure A are shown in Figures 7 and 8. As shown in Figure 8, the first-order mode shape function of the structure is symmetric and the second- and third-order mode shape functions of the structure are antisymmetric.

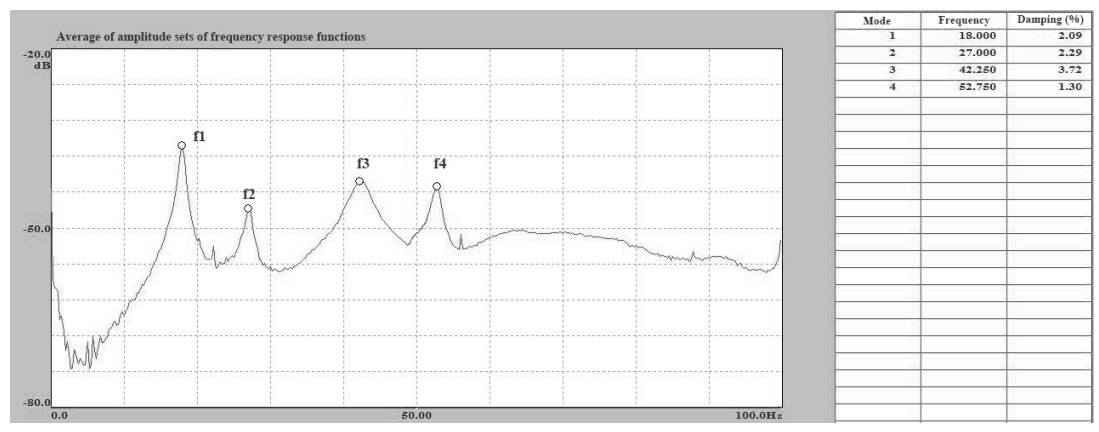

Figure 7. The natural frequency of the structure obtained from the identification process.

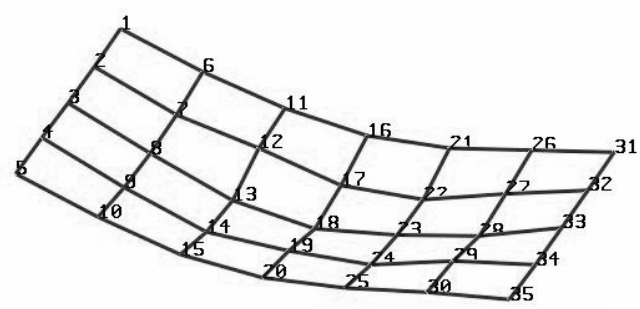

Mode 01 Frequency 17.89 Damping $1.91 \%$

(a)

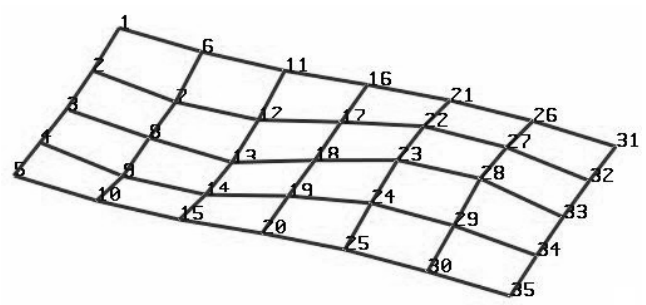

Mode 03 Frequency 42.10 Damping 3.72\%

(c)

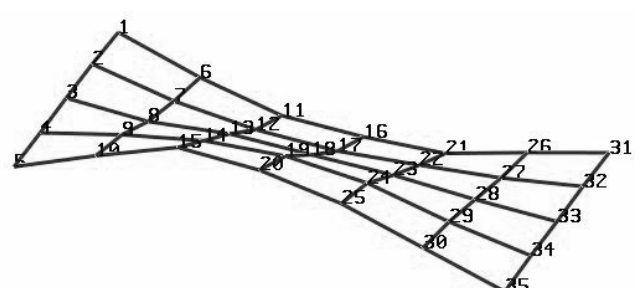

Mode 02 Frequency 26.98 Damping 2.29\%

(b)

Figure 8. First three modes and shape function of the original structure in Test 2: (a) first mode, frequency $17.89 \mathrm{~Hz}$, damping ratio $1.91 \%$; (b) second mode, frequency $26.98 \mathrm{~Hz}$, damping ratio $2.29 \%$; and (c) third mode, frequency $42.10 \mathrm{~Hz}$, damping ratio $3.72 \%$. 
The data of 35 channels measured by 35 test groups in this test set were processed to obtain the frequency response function between the excitation point and the measurement point, and the set total function composed of all the frequency response functions was used to discriminate the first four modes of the plate (Figure 9).

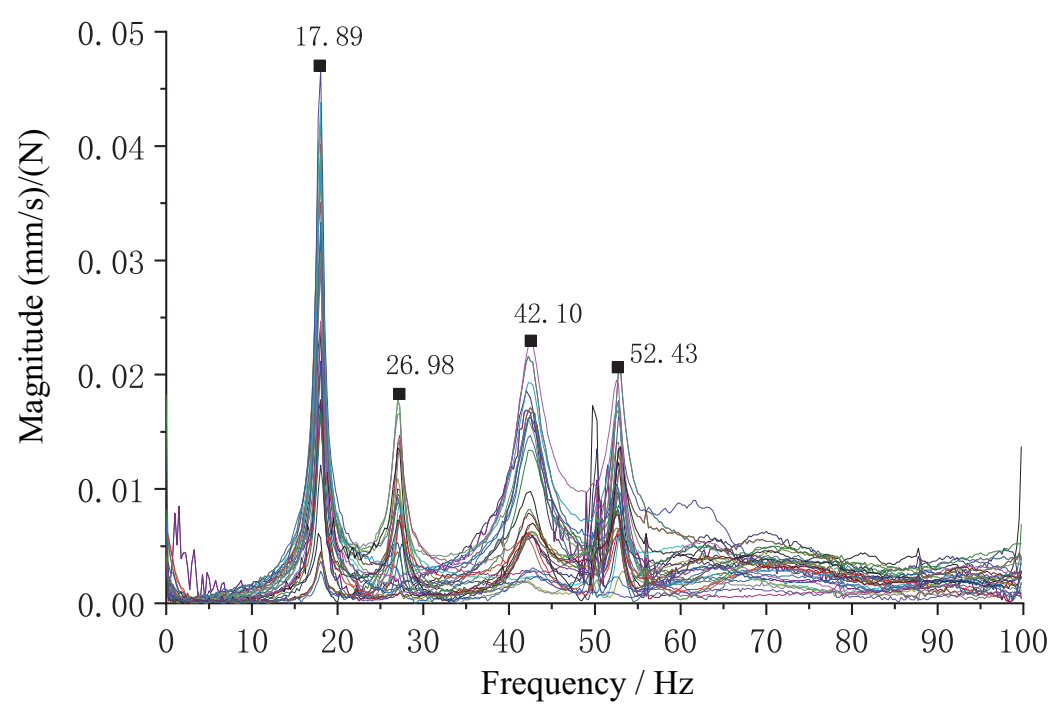

Figure 9. The set of frequency response functions between the excitation point and the measurement point in Test 2.

In Figure 9, the total function of all measured response functions identifies the first four modes of the plate: $17.89,26.98,42.10$, and $52.43 \mathrm{~Hz}$. The first three order frequencies of the Original Structures A-C were obtained using the method above, as shown in Table 5.

Table 5 shows that the first third-order mode of the original structure did not experience significant alterations during Phases I, III, and V, even though the activities of laying and removing different facings on the surface of the structure were carried out. Thus, it can be assumed that the dynamic characteristics of the original structure are not time-varying during the experiment. From the data in Table 5, the first three order natural frequencies of the Original Structures A-C are 17.90, 26.99, and $42.15 \mathrm{~Hz}$, respectively.

Table 5. Modal test results of Original Structures A-C.

\begin{tabular}{|c|c|c|c|c|c|c|c|}
\hline \multicolumn{7}{|c|}{ Model Test Results/Hz } & \multirow[t]{2}{*}{ Average Value/Hz } \\
\hline \multirow{4}{*}{ Original Structure A } & Test order & 1 & 2 & 3 & 4 & 5 & \\
\hline & First mode & 17.96 & 17.89 & 17.88 & 17.93 & 17.86 & 17.904 \\
\hline & Second mode & 27.05 & 26.98 & 26.97 & 27.02 & 26.95 & 26.994 \\
\hline & Third mode & 42.16 & 42.1 & 42.18 & 42.12 & 42.19 & 42.15 \\
\hline \multirow{4}{*}{ Original Structure B } & Test order & 9 & 10 & 11 & - & - & - \\
\hline & First mode & 17.98 & 17.85 & 17.88 & - & - & 17.903 \\
\hline & Second mode & 27.05 & 26.91 & 27.03 & - & - & 26.997 \\
\hline & Third mode & 42.25 & 42.10 & 42.12 & - & - & 42.157 \\
\hline \multirow{4}{*}{ Original Structure C } & Test order & 15 & 16 & 17 & - & - & - \\
\hline & First mode & 17.95 & 17.86 & 17.89 & - & - & 17.900 \\
\hline & Second mode & 27.06 & 26.92 & 27.00 & - & - & 26.993 \\
\hline & Third mode & 42.11 & 42.15 & 42.20 & - & - & 42.153 \\
\hline
\end{tabular}

\subsection{Modal Test Results of Ceramic Tile Structure}

For the plate structure with ceramic tile layer, the modal test results were similar to those of the Original Structure A. Figures 10 and 11 present the velocity time history and 
its power spectrum curve of Measurement Point 18 in Test 6 during the modal test of the ceramic tiled structure.

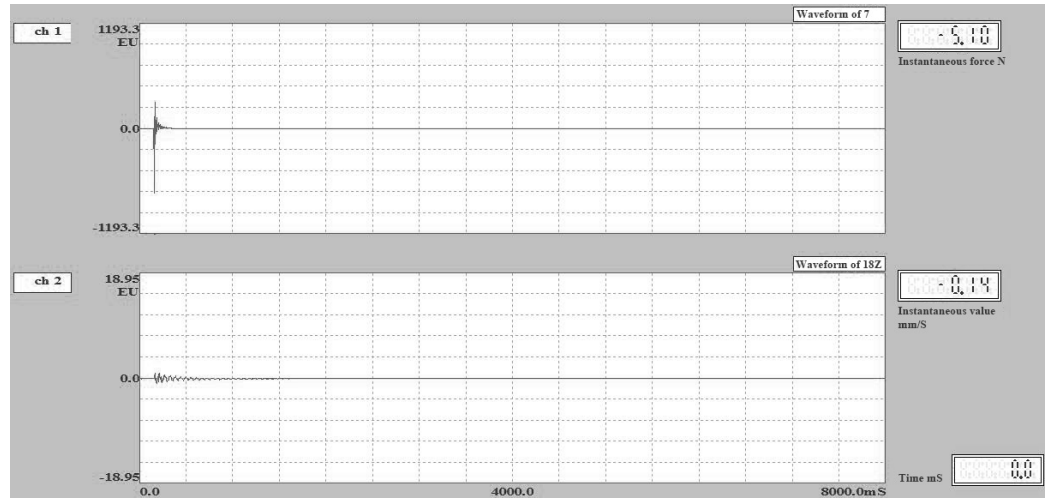

Figure 10. The velocity time curve of Measurement Point 18 in Test 6.

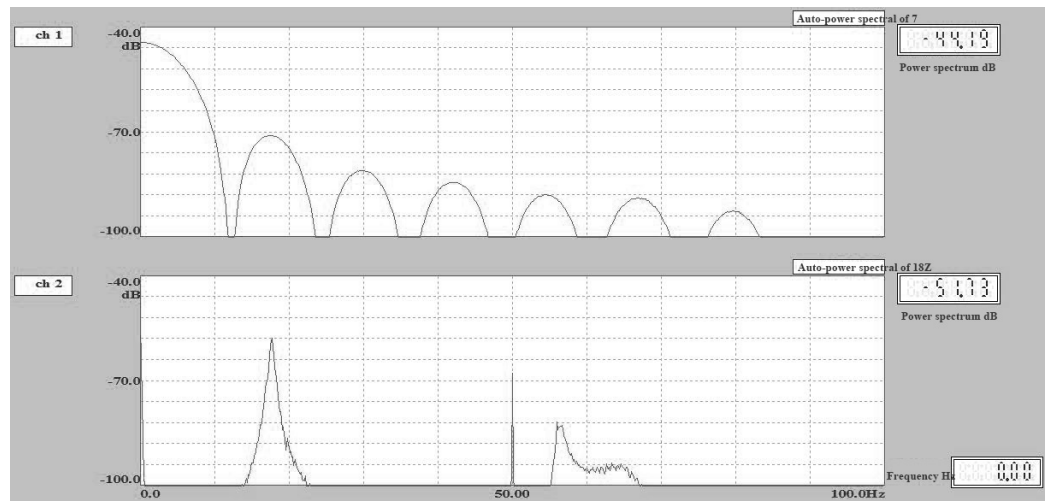

Figure 11. Velocity power spectrum curve of Point 18 in Test 6.

The identification results and shape function of the first three orders of the modes of the tile structure are shown in Figures 12 and 13. As shown in Figure 13, the first-order mode shape function of the structure is symmetric and the second- and third-order mode shape functions of the structure are antisymmetric.

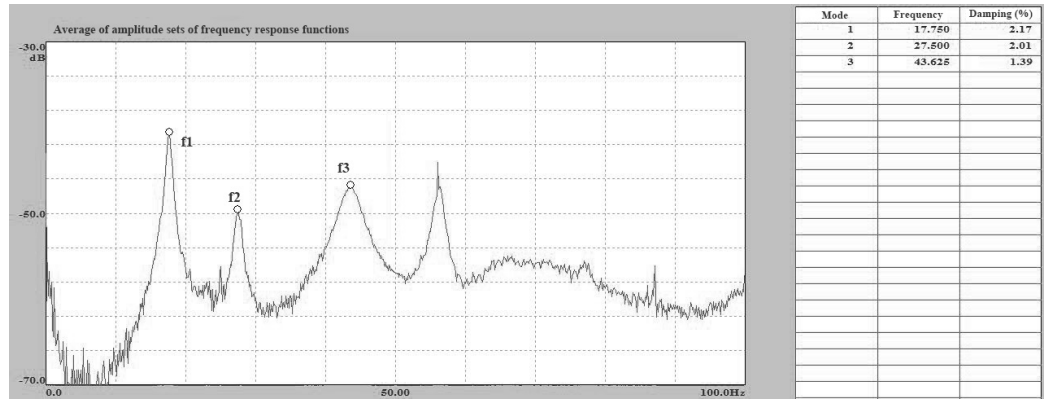

Figure 12. The natural frequency of the ceramic tile structure obtained from the identification process. 


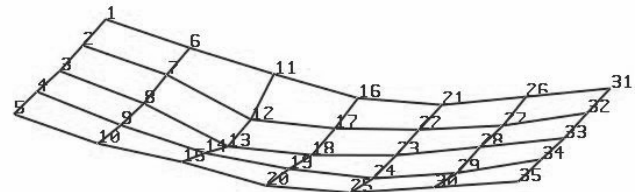

Mode 01 Frequency 17.61 Damping $2.17 \%$

(a)

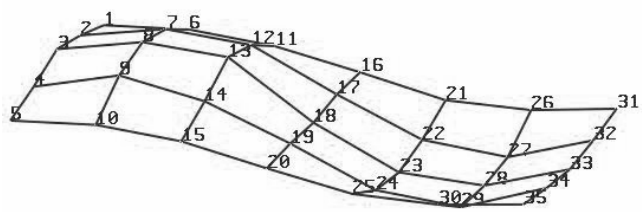

Mode 03 Frequency 43.63 Damping 1.39\%

(c)

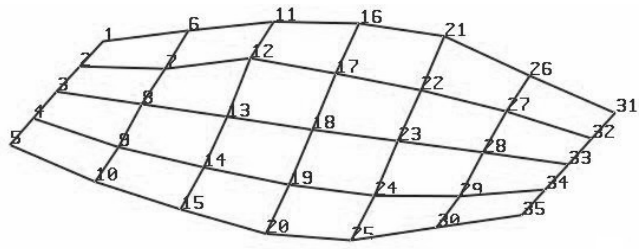

Mode 02 Frequency 27.44 Damping 2.01\%

(b)

Figure 13. First third modes and shape function of the original structure in Test 6: (a) first mode, frequency $17.61 \mathrm{~Hz}$, damping ratio $2.17 \%$; (b) second mode, frequency $27.44 \mathrm{~Hz}$, damping ratio $2.01 \%$; and (c) third mode, frequency $43.63 \mathrm{~Hz}$, damping ratio $1.39 \%$.

The velocity time history of 35 measurement points was processed to obtain the total set of frequency response functions for each measurement point corresponding to Test 6 , which is shown in Figure 14.

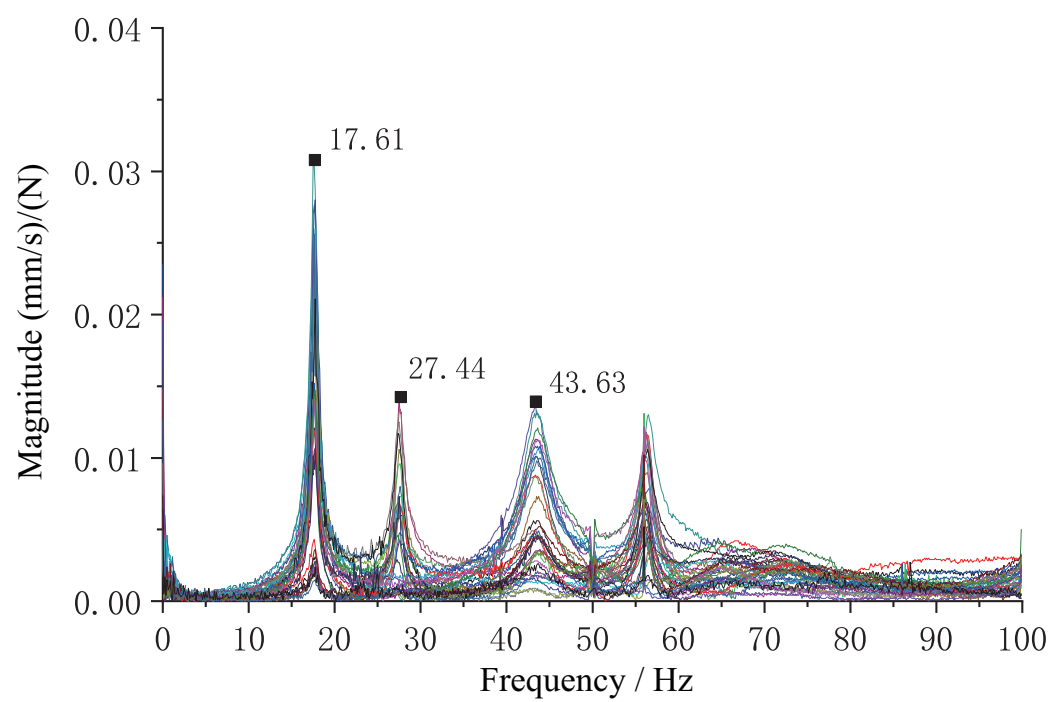

Figure 14. The set of frequency response functions between the excitation point and the measurement point in Test 6 .

As shown in Figures 13 and 14, the first three order frequencies of the structure measured in Test 6 are 17.61,27.44, and $43.63 \mathrm{~Hz}$. Table 6 shows the results of each modal test of the tiled structure, along with the average results of the three tests (Points 6-8). After the addition of the tiled surface, the first three order frequencies of the structure become $17.717,27.490$, and $43.560 \mathrm{~Hz}$. 
Table 6. Modal test results of the ceramic tile structure.

\begin{tabular}{lccccc}
\hline & Test Order & $\mathbf{6}$ & $\mathbf{7}$ & $\mathbf{8}$ & Average Value \\
\cline { 2 - 6 } Ceramic Tile Structure & First mode $/ \mathrm{Hz}$ & 17.61 & 17.82 & 17.72 & 17.717 \\
& Second mode $/ \mathrm{Hz}$ & 27.44 & 27.53 & 27.50 & 27.490 \\
& Third mode $/ \mathrm{Hz}$ & 43.63 & 43.51 & 43.54 & 43.560 \\
\hline
\end{tabular}

\subsection{Structure with a Terrazzo Layer}

The velocity time history and its power spectrum curve of Measurement Point 18 in Test 12 of the terrazzo structure are given in Figures 15 and 16.

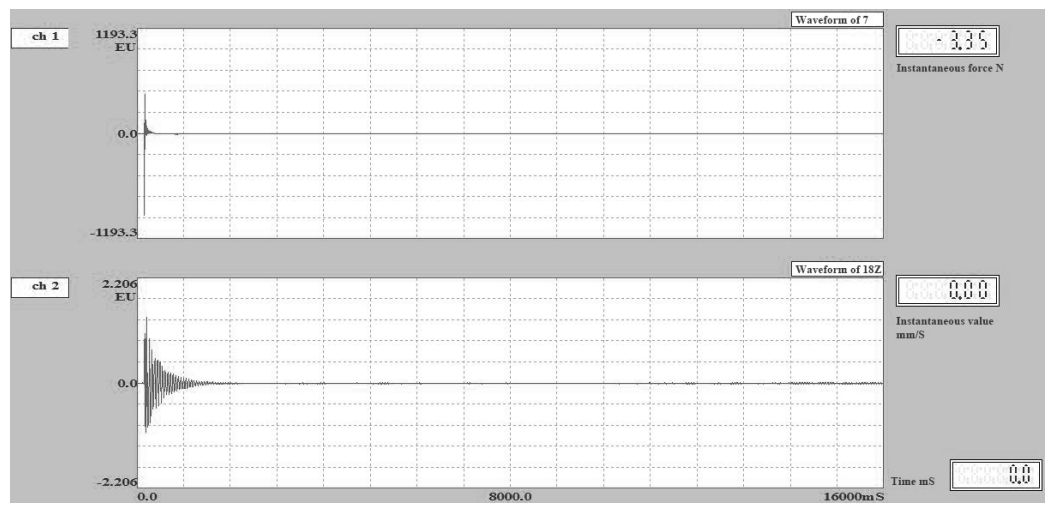

Figure 15. The velocity time curve of Measurement Point 18 in Test 12.

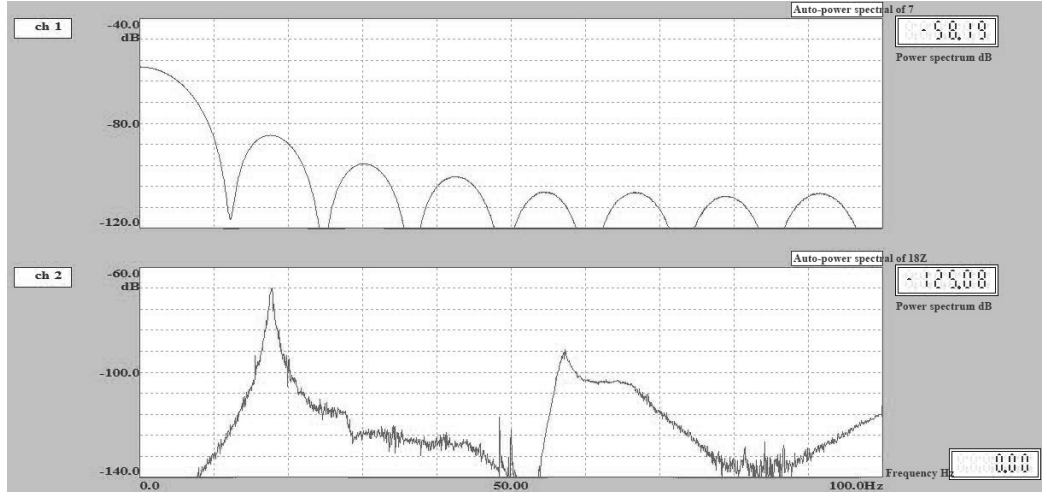

Figure 16. Velocity power spectrum curve of Point 18 in Test 12.

The identification results and shape function of the first three orders of the modes of the terrazzo structure are shown in Figures 17 and 18. Figure 18 shows that the first-order mode shape function of the structure is symmetric and the second- and third-order mode shape functions of the structure are antisymmetric.

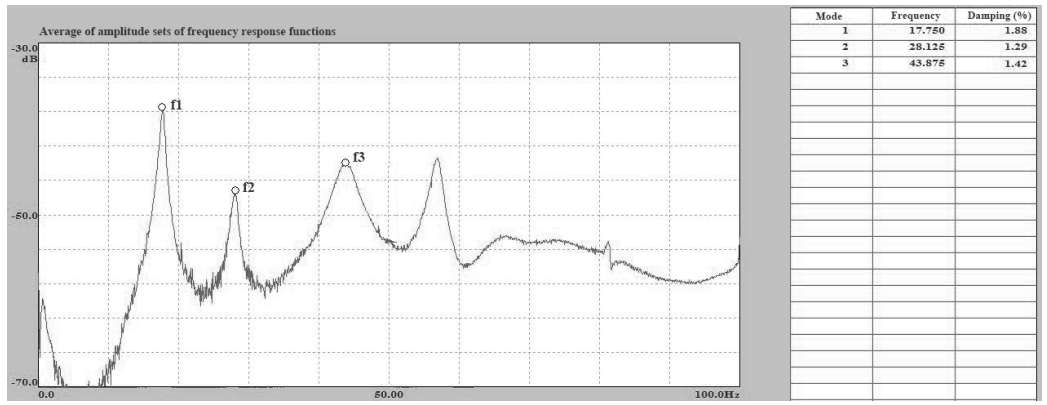

Figure 17. The natural frequency of the terrazzo structure obtained from the identification process. 


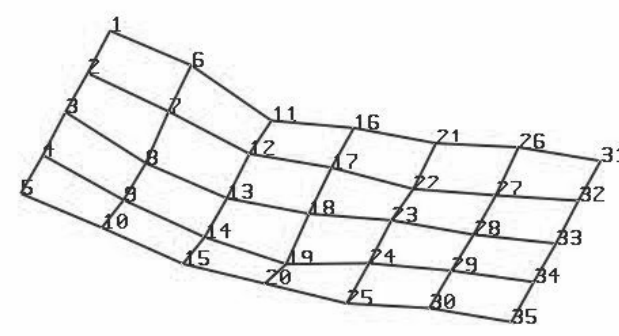

Mode 01 Frequency 17.75 Damping $1.88 \%$

(a)

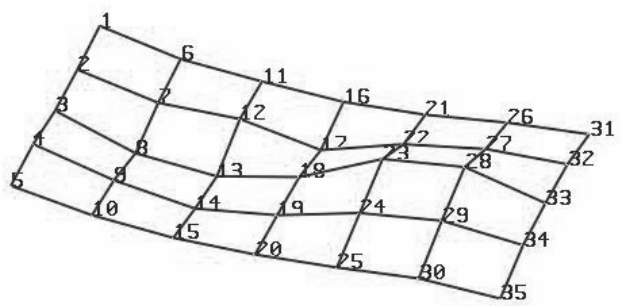

Mode 03 Frequency 43.88 Damping 1.42\%

(c)

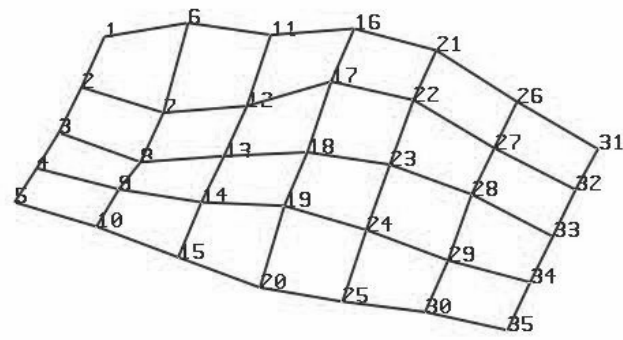

Mode 02 Frequency 28.13 Damping 1.29\%

(b)

Figure 18. First third modes and shape function of the original structure in Test 12: (a) first mode, frequency $17.75 \mathrm{~Hz}$, damping ratio $1.88 \%$; (b) second mode, frequency $28.13 \mathrm{~Hz}$, damping ratio $1.29 \%$; and (c) third mode, frequency $43.88 \mathrm{~Hz}$, damping ratio $1.42 \%$.

The velocity time history of 35 measurement points was processed to obtain the total set of frequency response functions for each measurement point corresponding to Test 12 , which is shown in Figure 19.

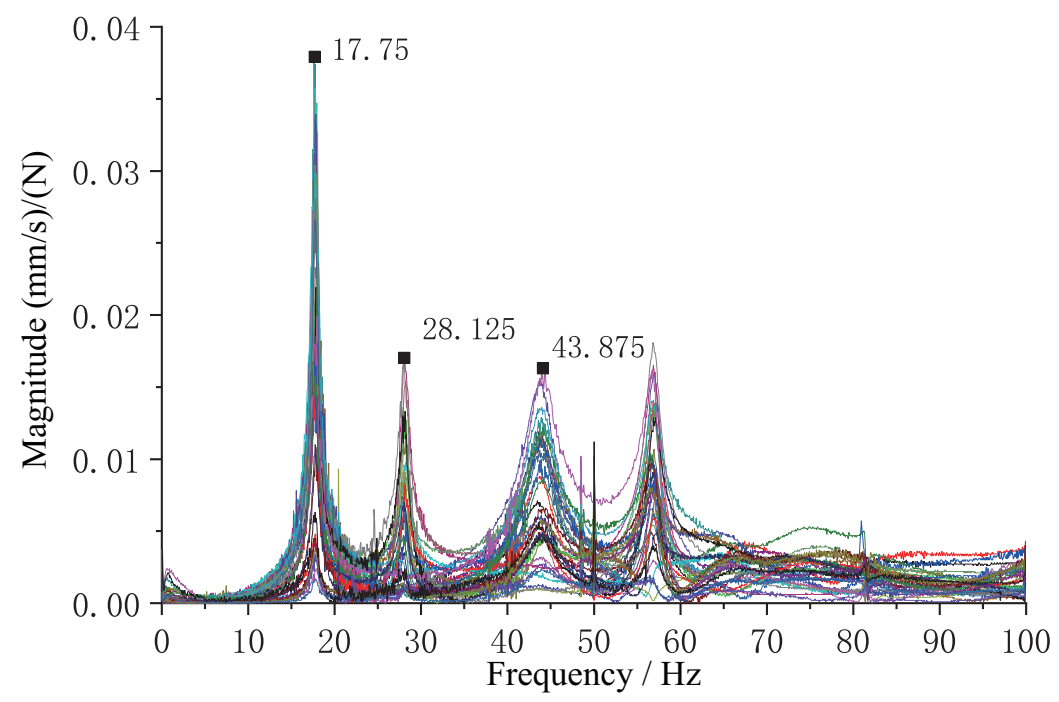

Figure 19. The set of frequency response functions between the excitation point and the measurement point in Test 12.

In Figures 18 and 19, the first three order frequencies of the structure measured in Test 12 are $17.75,28.125$, and $43.875 \mathrm{~Hz}$. Table 7 lists the natural frequencies of the terrazzo structure identified in three tests (Points 12-14). The average values of the three tests are obtained and the first three order natural frequencies of the structure with the decorative terrazzo surface layer are shown as $17.855,28.177$, and $43.923 \mathrm{~Hz}$. 
Table 7. Modal test results of the plate with terrazzo surfaces.

\begin{tabular}{lccccc}
\hline & Test Order & $\mathbf{1 2}$ & $\mathbf{1 3}$ & $\mathbf{1 4}$ & Average Value \\
\cline { 2 - 6 } Terrazzo Structure & First mode $/ \mathrm{Hz}$ & 17.750 & 17.940 & 17.875 & 17.855 \\
& Second mode $/ \mathrm{Hz}$ & 28.125 & 28.225 & 28.180 & 28.177 \\
& Third mode $/ \mathrm{Hz}$ & 43.875 & 43.940 & 43.955 & 43.923 \\
\hline
\end{tabular}

\subsection{Structure with a Marble Layer}

The velocity time history and its power spectrum curve of Measurement Point 18 in Test 19 of the marble structure are given in Figures 20 and 21.

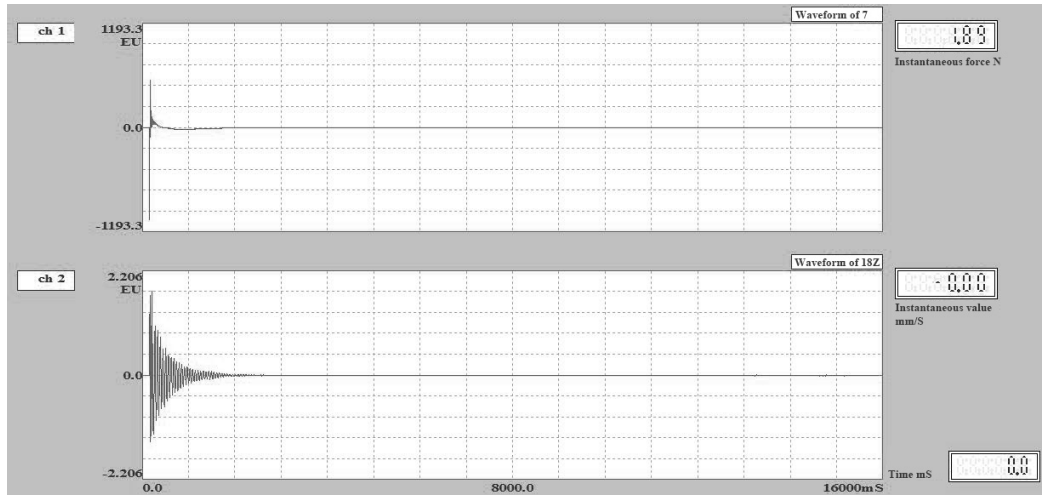

Figure 20. The velocity time curve of Measurement Point 18 in Test 19.

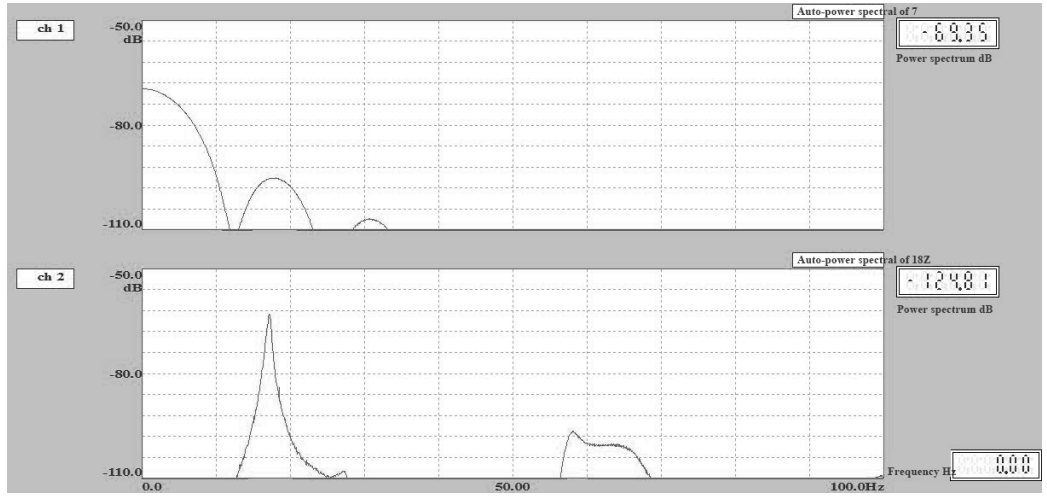

Figure 21. Velocity power spectrum curve of Point 18 in Test 19.

The identification results and shape function of the first three orders of the modes of the marble structure are shown in Figures 22 and 23. Figure 23 shows that the first-order mode shape function of the structure is symmetric and the second- and third-order mode shape functions of the structure are antisymmetric.
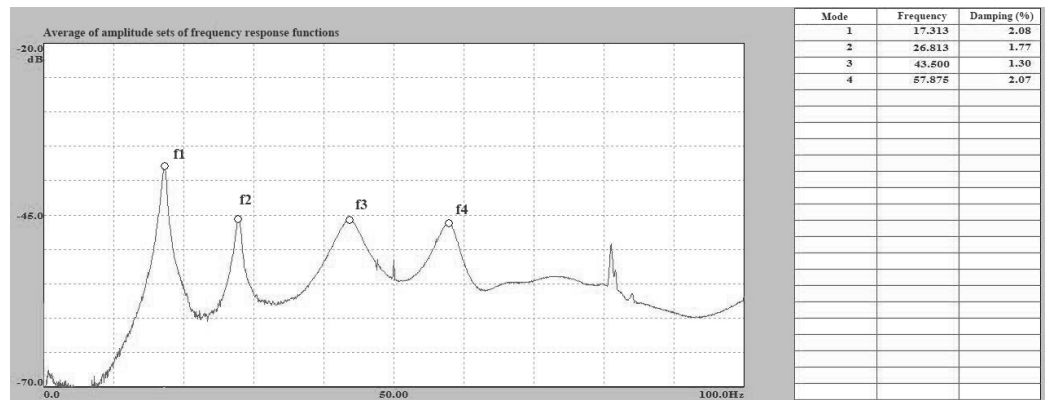

Figure 22. The natural frequency of the structure with marble surface obtained from the identification process. 


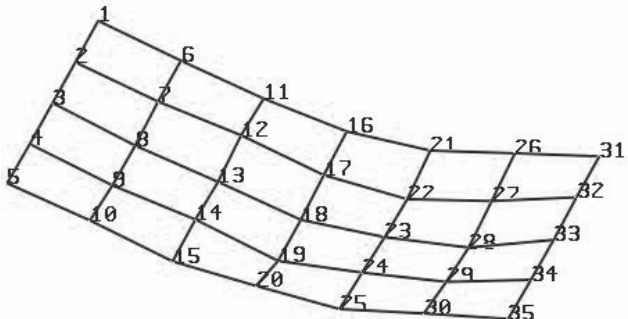

Mode 01 Frequency 17.32 Damping 2.08\%

(a)

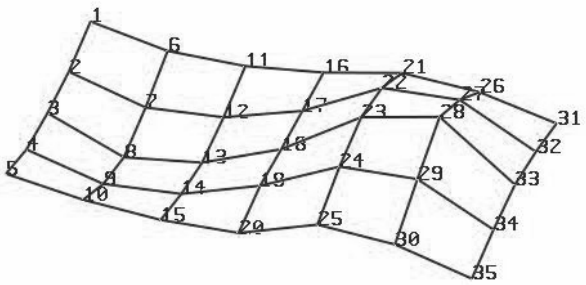

Mode 03 Frequency 43.50 Damping 1.30\%

(c)

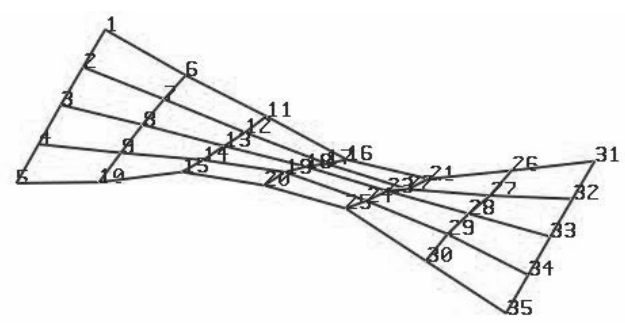

Mode 02 Frequency 26.84 Damping $1.77 \%$

(b)

Figure 23. First third modes and shape function of the original structure in Test 19: (a) first mode, frequency $17.32 \mathrm{~Hz}$, damping ratio $2.08 \%$; (b) second mode, frequency $26.84 \mathrm{~Hz}$, damping ratio $1.77 \%$; and (c) third mode, frequency $43.50 \mathrm{~Hz}$, damping ratio $1.30 \%$.

The velocity time history of 35 measurement points was processed to obtain the total set of frequency response functions for each measurement point corresponding to Test 19, which is shown in Figure 24.

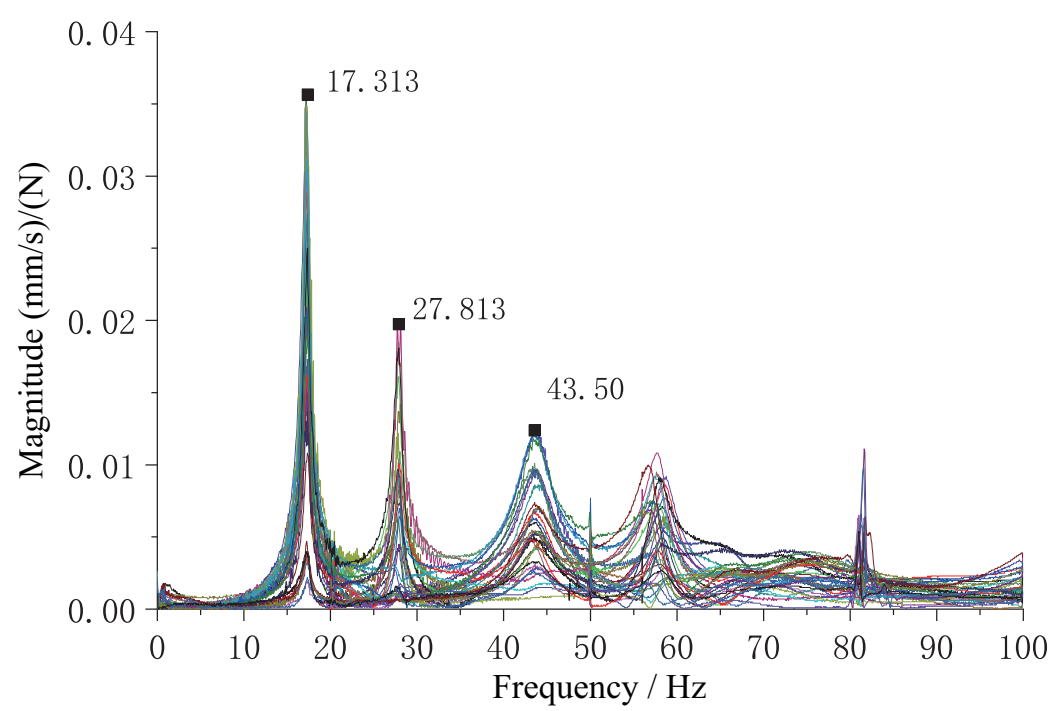

Figure 24. The set of frequency response functions between the excitation point and the measurement point in Test 19.

In Figures 23 and 24, the first three order frequencies of the structure measured in Test 12 are 17.313, 28.813, and $43.500 \mathrm{~Hz}$. Table 8 lists the natural frequencies of the marble structure identified in three tests (Points 18-20). The average values of the three tests are obtained and the first three order natural frequencies of the structure with the decorative terrazzo surface layer are shown as 17.361, 26.923, and $43.430 \mathrm{~Hz}$. 
Table 8. Modal test results of the plate with marble surfaces.

\begin{tabular}{cccccc}
\hline & Test order & $\mathbf{1 8}$ & $\mathbf{1 9}$ & $\mathbf{2 0}$ & Average Value \\
\cline { 2 - 6 } Marble Structure & First mode $/ \mathrm{Hz}$ & 17.360 & 17.313 & 17.410 & 17.361 \\
& Second mode $/ \mathrm{Hz}$ & 26.950 & 26.840 & 26.980 & 26.923 \\
& Third mode $/ \mathrm{Hz}$ & 43.370 & 43.500 & 43.420 & 43.430 \\
\hline
\end{tabular}

Based on the results of the structural modal tests with different surface layers in Sections 3.1-3.4, it is noticed that there is a general trend that the first-order frequency of the structure decreases after the surface layer is laid. However, the second- and third-order natural frequencies are increasing to some extent. For the convenience of comparison, we summarize the test results in Table 9. The assumption commonly adopted for the design is that the surface layer does not add stiffness to the original structure and the surface layer should be treated as an additional mass. Based on the assumption, the frequency of the structure is expected to be decreasing at all orders. In Table 9, there is a slight decrease in the first-order frequency of the structure with the decorative surface layer compared to that of the original structure, a result that is consistent with the assumption of additional mass. However, a comparison of the original structures shows that the second-order frequency of the structure with tile and terrazzo decorative surfaces are increasing, while the second-order frequency of the structure with marble surfaces are decreasing. Clearly, the test results contradict the hypothesis that the surface layer should only be treated as an additional mass. Furthermore, Table 9 shows that the third-order frequencies of the structures decorated with various decorative surfaces are all higher than that of the original structure, which further indicates that the decorative surfaces contribute not only to the additional mass but also to the additional stiffness of the original structure. In summary, the variation in the first three orders of frequency of the structure is the result of the combined effect of the additional mass of the surface layer and its additional stiffness.

Table 9. Summary of modal test results.

\begin{tabular}{ccccc}
\hline \multirow{2}{*}{ Mode Order } & \multicolumn{4}{c}{ Natural Frequency/Hz (Difference ${ }^{\#}$ ) } \\
\cline { 2 - 5 } & Original Structure & Ceramic Tile Layer & Terrazzo Layer & Marble Layer \\
\hline First mode & 17.900 & $17.717(-1.02 \%)$ & $17.855(-0.25 \%)$ & $17.361(-3.01 \%)$ \\
Second mode & 26.990 & $27.490(1.85 \%)$ & $28.177(4.40 \%)$ & $26.923(-2.48 \%)$ \\
Third mode & 42.150 & $43.560(3.35 \%)$ & $43.923(4.21 \%)$ & $43.430(3.04 \%)$ \\
\hline
\end{tabular}

${ }^{\#}$ Difference $=$ (Results of structure with additional surface layer - Results of original structure) $/$ Results of original structure $\times 100 \%$.

\section{Numerical Simulation of Decorative Surface Layers}

\subsection{The Introduction of Layered Shell Element}

The concept of layered shell element is based on the principle of composite mechanics, which divides a shell element into many layers, each of which can be set with different thicknesses and material properties (concrete, steel, etc.) as needed. In the FE calculation of the structure, by calculating the strain and curvature of the central layer of the shell unit, the strain of each layer is obtained from the strain and curvature of the central layer according to the assumption of flat section satisfied between the materials of each layer. Then, the corresponding stresses in each layer are obtained from the principal equation of each layer material, and the internal force of the whole shell unit is obtained by integration. The layered shell unit considers the coupling among in-plane bending, in-plane shear, and out-plane bending and reflects the spatial mechanical properties of the shell structure in a more comprehensive way. Miao et al. compared the simulation results with the experimental results to illustrate the accuracy of the layered shell model in the analysis of shear wall structures. It should be noted that the number of layers of a layered shell model has a positive effect on the out-of-plane performance of the shell, and the results become more accurate with the increasing layers [41]. 
This section draws on the laminated plate principle to simulate the case where the surface layer and the original structure are combined to work together as a single unit.

\subsection{Parameters of the Finite Element Model}

Sap2000 finite element software was used to model the original structure, structure with tile surface, structure with terrazzo surface, and structure with marble surface. The modal modes are derived from the eigenvector method.

The material properties used for the finite element simulation of the plate are presented as follows. The elastic modulus of concrete was taken as $3.0 \times 10^{4} \mathrm{MPa}$, Poisson's ratio was set as 0.2 , mass density was taken as $2426.92 \mathrm{~kg} / \mathrm{m}^{3}$, and concrete strength grade was taken as $31.4 \mathrm{MPa}$. HRB400 steel reinforcement was modeled according to the material properties: the elastic modulus was taken as $2.1 \times 10^{5} \mathrm{MPa}$, Poisson's ratio was taken as 0.3 , and mass density was taken as $7850 \mathrm{~kg} / \mathrm{m}^{3}$.

The thickness of the floor cover was taken as $122 \mathrm{~mm}$ based on the average value of the actual measurement results. Each beam was modeled with the frame section inside Sap2000 according to the actual size. The reinforced concrete floor was simulated by a nonlinear layered shell unit, the reinforcement in the slab was diffused into the reinforcement mesh layer according to the actual position, and the number of integral points of concrete layer and reinforcement layer was taken as 4 . The node offset displacement of the four sides was adjusted so that the original structural slab surface and the top surface of the beam were on the same level. The laid surface layer was simulated as a certain thickness of concrete layer added to the original floor surface, and the parameters were adopted from the C30 concrete material parameters mentioned above, as shown in Figure 25. In terms of load, the slab surface load was taken as $2927.4 \mathrm{~N} / \mathrm{m}^{2}$.

The appropriate definition of the grid size has a significant impact on the computational efficiency and the accuracy of the results. Due to the nonlinear behavior of concrete, the scale of division needs to be selected properly to achieve a balance between accuracy and efficiency. In the experiment, the thickness of the original structural part and the decorative surface part of reinforced concrete were different, so the grid was divided into one grid along the thickness direction. The division accuracy was improved along the length and width of the slab by setting the grid size as $125 \mathrm{~mm} \times 125 \mathrm{~mm}$, and the layer integration points were taken as 4 . In this study, the four layers of the layered shell unit for simulating the slab were the reinforcement layer in both directions, the concrete layer of the original structure, and an additional concrete layer that served as an equivalent decorative surface layer. The slab was divided equally into 48 segments along the long side and 24 segments along the short side, giving a total of 1152 square grid units. The mesh division of the plate and its extension view are shown in Figure 25.

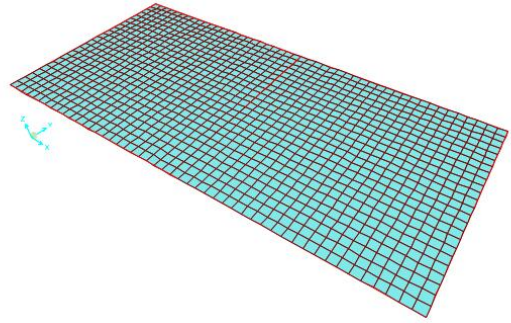

(a)

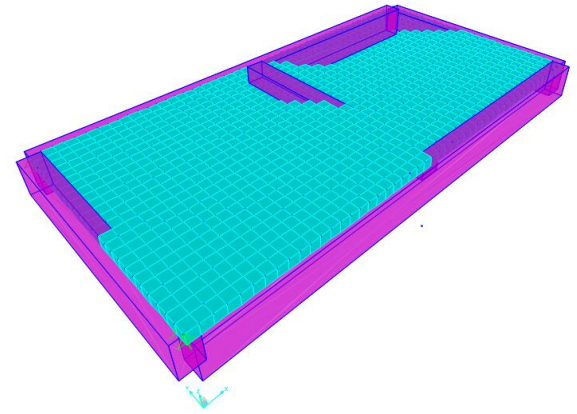

(b)

Figure 25. Finite element model of the plate: (a) the meshing of the plate; and (b) extension view of the plate model. 


\subsection{Comparison of Experimental Results and Simulation Results}

\subsubsection{Finite Element Results of the Original Structure}

The mode results of each order of the original structure are shown in Table 10. Tthe measured mean values of the frequencies are also listed in Table 10. As can be seen in the table, the first- and second-order frequencies of the finite element model are close to the measured values, while the third-order frequency differs by $7.391 \%$, which is within the practical error limit. The finite element simulation is accurate enough and can be used for the simulation of the stiffness contribution of the face layer to the original structure. The shape function of the first four order modes of the structure calculated by the Sap2000 model is shown in Figure 26. In this study, we focus only on the first three modes of the structure. A comparison of the measured structural modes with the finite element simulation results shows that they are in good agreement in the first three orders, as presented in Figures 23 and 25.

Table 10. Comparison between numerical simulation and experimental results.

\begin{tabular}{cccc}
\hline Mode Order & Measured Value/Hz & $\begin{array}{l}\text { Simulation } \\
\text { Results/Hz }\end{array}$ & Difference \# \\
\hline First mode & 17.900 & 17.929 & $0.162 \%$ \\
Second mode & 26.990 & 26.986 & $-0.015 \%$ \\
Third mode & 42.150 & 39.035 & $-7.391 \%$ \\
\hline
\end{tabular}

${ }^{\#}$ Difference $=($ numerical analysis results - measured value $) /$ measured value $\times 100 \%$.

Mode $1 \mathrm{~T}=0.05578$ s: $\mathrm{f}=17.22554 \mathrm{~Hz}$

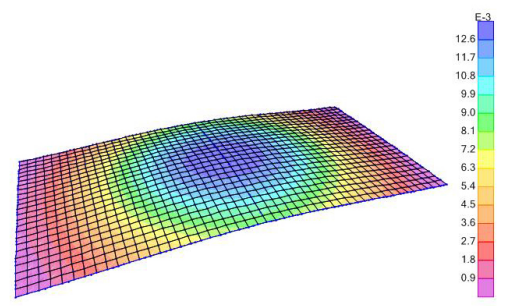

(a)
Mode $2 \mathrm{~T}=0.03706 \mathrm{~s}: \mathrm{f}=26.98561 \mathrm{~Hz}$

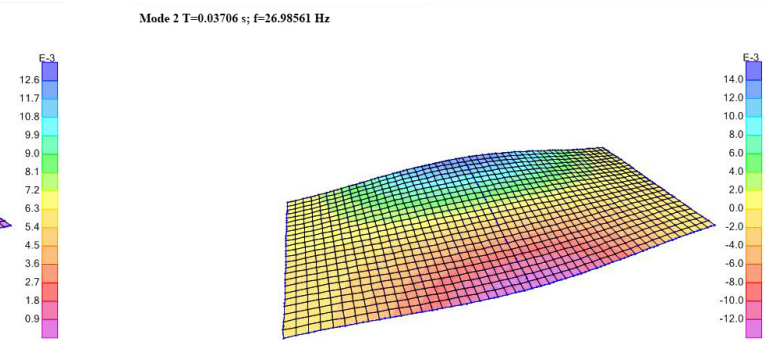

(b)

Mode $3 \mathrm{~T}=0.02562$ s; $\mathrm{f}=3.03466 \mathrm{H} z$

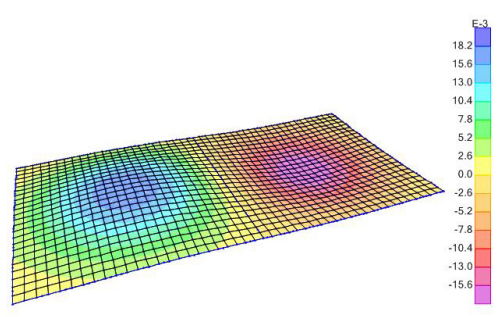

(c)

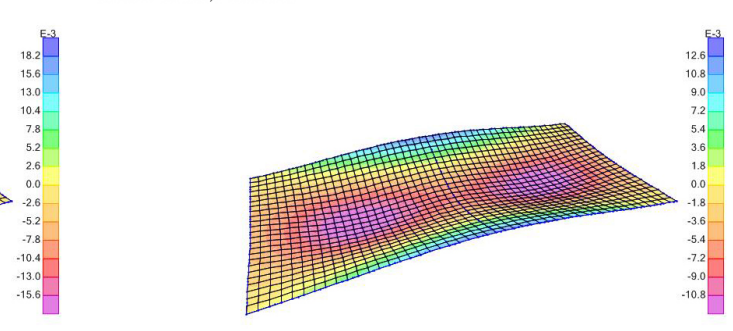

(d)

Figure 26. The first fourth order mode of structure obtained from the simulation: (a) first mode; (b) second mode; (c) third mode; and (d) fourth mode.

However, it is worth noting that the measured values of the third-order frequency of the structure are obviously different from the FE simulation results if compared to the first two order frequencies of the structure, which deserves an in-depth discussion.

As shown in Figure 26a, the maximum displacement of the first-order vibration mode of the structure is located at the center of the floor slab, which coincides with the center of the secondary beam. The mode shape function is characterized by a double maximum displacement of both the floor slab and the secondary beam. Similarly, the second-order shape function of the structure exhibits the combined deformation of the side beams and 
the floor slab. In this case, the maximum value of the vibration mode is at the center of the edge beam as well as the center of the slab edge, which are coincident. The edge beam and the floor slab reach the maximum value of the shape function simultaneously (Figure 26a). However, the third-order shape function of the structure shows a different pattern. As shown in Figure 26c, the third-order mode shape of the structure exhibits local floor vibration. Due to the existence of the intermediate secondary beam, the entire floor slab is divided into two parts, and it is local vibrations of each part that form the third-order vibration pattern of the structure. Significantly different from the deformation pattern presented in the first and second vibration modes when the beam and slab simultaneously reach the maximum value of the shape function, the third-order mode demonstrates that the edge beam and the middle secondary beam are not at the maximum value of the mode shape; edge beams and intermediate secondary beams are rarely involved in local slab vibration as well.

In summary, the deformation patterns of the first and second orders of the structure are the same, while the deformation patterns of the third order of the structure are significantly different from the first two orders. This may explain why we can observe the error jump in the third mode.

\subsubsection{Simulation Results for the Plates with Three Types of Surface}

As the frequency of the structure is correlated with both the stiffness and the mass, the following assumptions were applied to examine the impact of the surface layer on the dynamic properties of the structure using Sap2000 finite element software. The surface layer was modeled as a specific thickness of C30 concrete layer (called additional layer) laid on the surface of the original structure, the mass of this layer was taken as the actual mass of the surface layer, and the rest of the parameters were taken from the C 30 concrete material parameters. The enumeration method was adopted to explore the thickness of the additional layer, and the thickness range of the additional layer was set from 0 to $80 \mathrm{~mm}$ at $4 \mathrm{~mm}$ intervals. The variation law of the additional layer thickness with simulation is given in Figure 27 for three different surface structure frequencies.

Figure 27 shows that the natural frequency of the floor cover tends to grow with the increase of the thickness of the additional layer. The curvature of the growth curve reveals such a relationship: with the growing thickness of the additional layer in increments $\Delta f$, the increments of the first three orders frequencies grow with $\Delta f_{3}>\Delta f_{2}>\Delta f_{1}$. From a comparison of the FEM simulation results with the measured values (the dashed lines representing the measured frequencies in Figure 27), it is revealed that the first- and secondorder simulated values are close to the measured values when the additional layer thickness is in the range of $29-31 \mathrm{~mm}$.

Table 11 shows the comparison between the simulated and measured results of the floor slab modes when the thickness of the additional layer is 29,30 , and $31 \mathrm{~mm}$. It can be noticed that, if the decorative surface layer is simulated as a concrete layer of $29-31 \mathrm{~mm}$, the difference between the first- and second-order natural frequencies of the numerical simulation results and the measured values is less than $1 \%$. Despite the error of the third-order frequency reaching $7.68 \%$, the simulation results are reliable as the third-order frequency of the original model has a certain error with the measured value, which can be seen in Table 10. In summary, the first three modes of the numerical model agree well with the measured values when the decorative surface layer is simulated as a concrete layer of 29-31 mm in thickness. It indicates that the contribution of the decorative surface layer to the structural stiffness and mass can be considered as a concrete laminated layer of 29-31 $\mathrm{mm}$ in thickness. 
Table 11. Results of natural mode of numerical model and comparison with measured values for additional layer thickness of 29-31 mm.

\begin{tabular}{|c|c|c|c|c|c|c|c|}
\hline \multirow{5}{*}{ Structure with ceramic tile } & \multirow{2}{*}{ Thickness of the Additional Layer } & \multicolumn{2}{|c|}{$29 \mathrm{~mm}$} & \multicolumn{2}{|c|}{$30 \mathrm{~mm}$} & \multicolumn{2}{|c|}{$31 \mathrm{~mm}$} \\
\hline & & Simulation & Differnece $\#$ & Simulation & Difference & Simulation & Difference \\
\hline & First mode & 17.692 & $-0.14 \%$ & 17.738 & $0.12 \%$ & 17.736 & $0.11 \%$ \\
\hline & Second mode & 26.985 & $-1.87 \%$ & 27.380 & $-0.40 \%$ & 27.781 & $1.05 \%$ \\
\hline & Third mode & 40.763 & $-6.86 \%$ & 40.935 & $-6.41 \%$ & 41.082 & $-6.03 \%$ \\
\hline \multirow{5}{*}{ Structure with Terrazzo Surface } & Thicloce of the Additional I avor & \multicolumn{2}{|c|}{$29 \mathrm{~mm}$} & \multicolumn{2}{|c|}{$30 \mathrm{~mm}$} & \multicolumn{2}{|c|}{$31 \mathrm{~mm}$} \\
\hline & Inickness or the Adaitional Layer & Simulation & Difference & Simulation & Difference & Simulation & Difference \\
\hline & First mode & 17.877 & $0.13 \%$ & 17.916 & $0.34 \%$ & 17.958 & $0.57 \%$ \\
\hline & Second mode & 28.190 & $0.05 \%$ & 28.297 & $0.42 \%$ & 28.380 & $0.72 \%$ \\
\hline & Third mode & 41.284 & $-6.39 \%$ & 41.453 & $-5.96 \%$ & 41.602 & $-5.58 \%$ \\
\hline \multirow{5}{*}{ Structure with marble surface } & Thicknesc of the Additional I aver & \multicolumn{2}{|c|}{$29 \mathrm{~mm}$} & \multicolumn{2}{|c|}{$30 \mathrm{~mm}$} & \multicolumn{2}{|c|}{$31 \mathrm{~mm}$} \\
\hline & 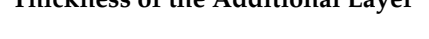 & Simulation & Difference & Simulation & Difference & Simulation & Difference \\
\hline & First mode & 17.356 & $-0.03 \%$ & 17.376 & $0.08 \%$ & 17.426 & $0.37 \%$ \\
\hline & Second mode & 26.921 & $-0.01 \%$ & 26.956 & $0.12 \%$ & 27.005 & $0.30 \%$ \\
\hline & Third mode & 40.333 & $-7.68 \%$ & 40.563 & $-7.07 \%$ & 40.688 & $-6.74 \%$ \\
\hline
\end{tabular}

${ }^{\#}$ Difference $=$ (numerical analysis results - measured value) $/$ measured value $\times 100 \%$.

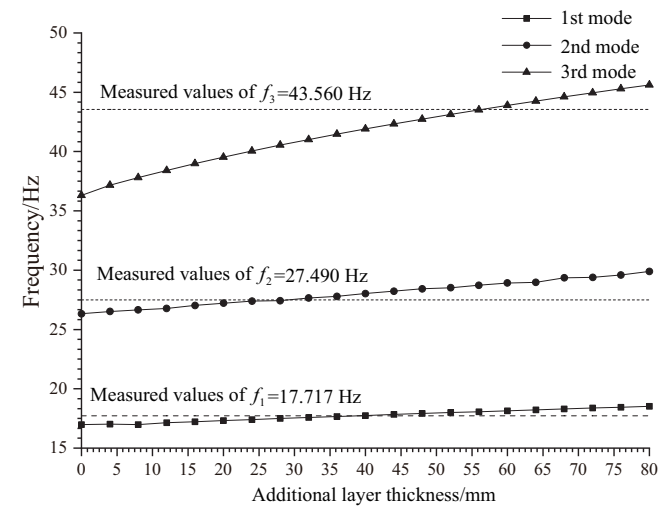

(a)

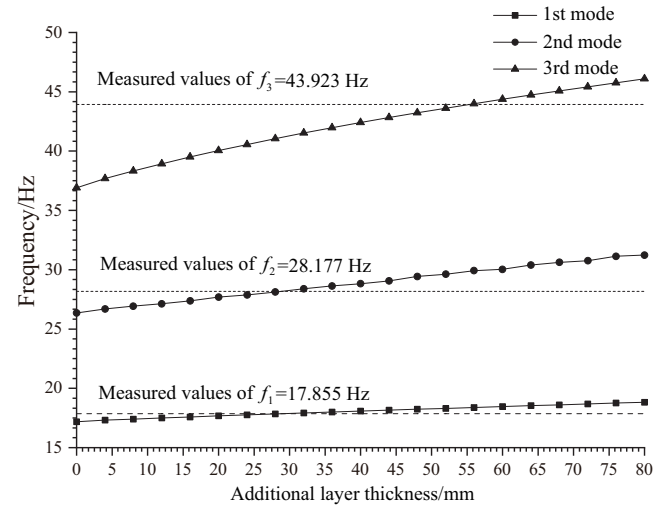

(b)

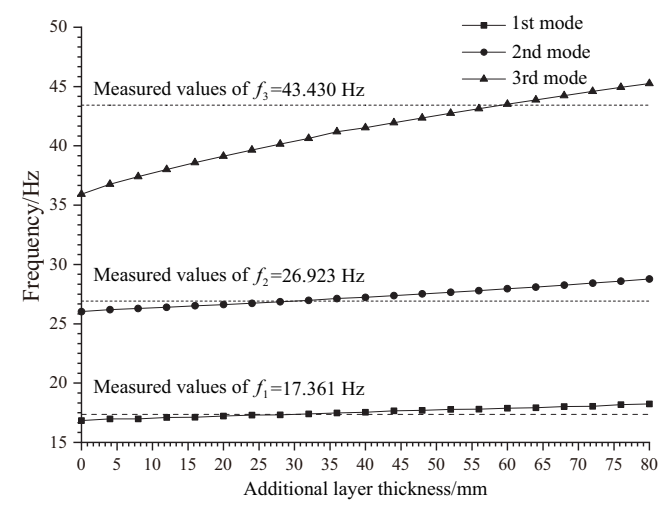

(c)

Figure 27. Frequency variation of surface structure with additional layer thickness: (a) structure with ceramic tile surface; (b) structure with ceramic terrazzo surface; and (c) structure with ceramic marble surface.

\section{Discussion and Conclusions}

In actual design process and vibration tests, there tend to be non-negligible errors between the measured vertical frequencies of the floor and the FE calculations after the decorative coverings are laid. Many studies have shown that the contribution of the decorative layer to the dynamic properties of the structure not only lies in the increase of mass but also in its non-negligible effect on the stiffness. It is thus necessary to explore the effect of different decorative finishes on the structural dynamic properties of floor 
slabs, with an aim to provide designers with a simple and feasible solution to consider the stiffness contribution of decorative finishes to floor slabs.

This paper describes the process of setting up the test platform and elaborates how to conduct the tests on the plates with various surface layers and material properties in each stage. After that, the mode test method in this paper is introduced, and the reliability of the software to identify the modal frequencies is verified by using a total set of frequency response functions. In addition, the modal frequencies of each order of the different surface layer structures are obtained. Based on the theory of laminated plate, the decorative surface layer was simulated as an additional layer of the structure by using the layered shell unit, and the Sap2000 finite element software was used to simulate the surface layer structure and analyze the influence of the surface layer on the structural frequency. The major conclusions are as follows:

1. The mode tests with three different surface layers reveal that the first-order frequency of the structure is decreased after the surface layer is laid, while the second- and thirdorder frequencies are increased, which indicates that it is inappropriate to consider the surface layer solely as an additional mass, as it will cause a decrease in the frequency of each order of the structure.

2. Modal evaluation of the finite element model reveals that the greater is the thickness of the additional layer of the structure, the higher is the frequency of the structure, and the third-order frequency changes more significantly than the first two order frequencies.

3. A comparison between the results of the finite element model and the experimental values makes it evident that a consideration of the contribution of the surface layer to the structural mass and stiffness prompts treating the surface layer as an additional concrete layer. The mass of the additional layer is taken as the actual weight of the surface layer, and the thickness of the additional layer is suggested to be $29-31 \mathrm{~mm}$, at which point the results of the FE calculation and the measured value can be in good agreement.

It is undeniable that our tests only consider three types of surface layers, ceramic tile, marble, and terrazzo, and different results may be achieved with other varied surface layers on the structural stiffness. The differences between the third mode frequency of the slab calculated by the finite element model with experimental results are relatively more obvious compared to the first two modes, which indicates that a more realistic finite element model can be used for calculations in future studies.

In summary, based on the results of our research, we believe that the effect of the decorative surface on the outward stiffness of the floor slab needs to be taken into account when the assessment of the dynamic properties of the floor slab at the design stage is conducted. Our proposal is that the stiffness contribution of the decorative surface to the floor slab should be simulated with a $29-31 \mathrm{~mm}$ thick concrete surface, while the effect of its mass on the dynamic properties of the floor slab should be simulated by an additional load equal to the actual weight of the decorative surface. For structure designers, it is a simple and effective approach to determine the dynamic properties of the slab.

Author Contributions: Conceptualization, H.L. and Y.Z.; methodology, Y.Z.; software, H.L.; validation, H.L., W.X., and P.W.; formal analysis, H.L. and Y.Z.; investigation, Y.Z.; resources, Y.Z.; data curation, Y.Z.; writing-original draft preparation, H.L.; writing-review and editing, H.L.; visualization, H.L.; supervision, Z.Z.; project administration, Z.Z.; and funding acquisition, Z.Z. All authors have read and agreed to the published version of the manuscript.

Funding: This study was supported by the National Natural Science Foundation of China (Grant No. 51278106), Project of Science and Technology Research and Development Program of China Railway Corporation (Grant No. P2018G049), and Key R\&D project of Jiangsu Province (Grant No. BE2019107).

Institutional Review Board Statement: Not applicable. 
Informed Consent Statement: Informed consent was obtained from all subjects involved in the study.

Data Availability Statement: The authors confirm that the data supporting the findings of this study are available within the article.

Acknowledgments: The authors thank HY Liang (Soochow University) for revising the manuscript and polishing the language.

Conflicts of Interest: The authors declare no conflict of interest.

\section{References}

1. Varela, W.D.; Battista, R.C. Control of vibrations induced by people walking on large span composite floor decks. Eng. Struct. 2011, 33, 2485-2494. [CrossRef]

2. Mutoh, A.; Masuda, A.; Itoh, T. Development of floor system using RC curved and folded surfaces. In Proceedings of the IASS Annual Symposia, Tokyo, Japan, 27 September 2016; Volume 2016, pp. 1-7.

3. Ahmed, I.M.; Tsavdaridis, K.D. The evolution of composite flooring systems: Applications, testing, modelling and eurocode design approaches. J. Constr. Steel Res. 2019, 155, 286-300. [CrossRef]

4. Szydlowski, R.; Labuzek, B. Post-Tensioned Concrete Long-Span Slabs in Projects of Modern Building Construction. In Proceedings of the IOP Conference Series: Materials Science and Engineering, Busan, Korea, 25-27 August 2017; Volume 245, p. 022065.

5. Zhao, X.; Huang, Y.; Fu, H.; Wang, Y.; Wang, Z.; Sayed, U. Deflection Test and Modal Analysis of Lightweight Timber Floors. J. Bioresour. Bioprod. 2021. [CrossRef]

6. Bachmann, H. Vibration upgrading of gymnasia, dance halls and footbridges. Struct. Eng. Int. 1992, 2, 118-124. [CrossRef]

7. Quast, U. Schwingungsverhalten der Tribünen des Volksparkstadions Hamburg. Beton-Und Stahlbetonbau 1993, 88, 233-236. [CrossRef]

8. Kasperski, M. Actual Problems with Stand Structures Due to Spectator-Induced Vibrations. In Proceedings of the Eurodyn, Florence, Italy, 5-8 June 1996; Volumme 96, pp. 455-461.

9. Dallard, P.; Fitzpatrick, T.; Flint, A.; Low, A.; Smith, R.R.; Willford, M.; Roche, M. London Millennium Bridge: Pedestrian-induced lateral vibration. J. Bridge Eng. 2001, 6, 412-417. [CrossRef]

10. Sachse, R. The Influences of Human Occupants on the Dynamic Properties of Slender Structures. Ph.D. Thesis, University of Sheffield, Sheffield, UK, 2003.

11. Nakamura, S.I.; Kawasaki, T. Lateral vibration of footbridges by synchronous walking. J. Constr. Steel Res. 2006, 62, 1148-1160. [CrossRef]

12. Eckhardt, B.; Ott, E.; Strogatz, S.H.; Abrams, D.M.; McRobie, A. Modeling walker synchronization on the Millennium Bridge. Phys. Rev. E 2007, 75, 021110. [CrossRef]

13. Macdonald, J.H. Lateral excitation of bridges by balancing pedestrians. Proc. R. Soc. A Math. Phys. Eng. Sci. 2009, 465, 1055-1073. [CrossRef]

14. Ahmadi, E.; Caprani, C. Damping and frequency of human-structure interaction system. In Proceedings of the MATEC Web of Conferences, San Diego, CA, USA, 12-13 August 2015; Volume 24, p. 07006.

15. Shahabpoor, E.; Pavic, A.; Racic, V.; Zivanovic, S. Effect of group walking traffic on dynamic properties of pedestrian structures. J. Sound Vib. 2017, 387, 207-225. [CrossRef]

16. He, W.; Xie, W.P. Characterization of stationary and walking people on vertical dynamic properties of a lively lightweight bridge. Struct. Control Health Monit. 2018, 25, e2123. [CrossRef]

17. Devin, A.; Fanning, P.; Pavic, A. Modelling effect of non-structural partitions on floor modal properties. Eng. Struct. 2015, 91, 58-69. [CrossRef]

18. Devin, A.; Fanning, P. Impact of nonstructural components on modal response and structural damping. In Topics on the Dynamics of Civil Structures; Springer: Berlin/Heidelberg, Germany, 2012; Volume 1, pp. 415-421.

19. Petrovic, S.; Pavic, A. Effects of non-structural partitions on vibration performance of floor structures: A literature review. In Proceedings of the International Conference on Structural Dynamics, EURODYN 2011, Leuven, Belguim, 4-6 July 2011.

20. Reynolds, P.; Pavic, A. Effects of false floors on vibration serviceability of building floors. I: Modal properties. J. Perform. Constr. Facil. 2003, 17, 75-86. [CrossRef]

21. Pernica, G. Effect of architectural components on the dynamic properties of a long-span floor system. Can. J. Civ. Eng. 1987, 14, 461-467. [CrossRef]

22. Lenzing, H. Durch Menschen Induzierte Schwingungen; Universität Hannover: Hanover, Germany, 1988.

23. Ellis, B.; Ji, T. Human-structure interaction in vertical vibrations. Proc. Inst. Civ. Eng. Struct. Build. 1997, 122, 1-9. [CrossRef]

24. Lenzen, K.H. Vibration of steel joist-concrete slab floors. AISC. Eng. J. 1966, 3, 133-136.

25. Polensek, A. Damping capacity of nailed wood-joist floors. Wood Sci. For. Prod. Res. Soc. Madison 1975, 2, $141-151$.

26. Rainer, J.; Pernica, G. Vibration characteristics of a floor sample. Acoust. Soc. Am. J. 1981, 69, S25. [CrossRef]

27. Brownjohn, J.M. Energy dissipation from vibrating floor slabs due to human-structure interaction. Shock Vib. 2001, 8, 315-323. [CrossRef] 
28. Živanović, S.; Diaz, I.; Pavić, A. Influence of walking and standing crowds on structural dynamic properties. In Proceedings of the Conference \& Exposition on Structural Dynamics (IMAC XXVII), Orlando, FL, USA, 9-12 February 2009.

29. Littler, J. Full-scale testing of large cantilever grandstands to determine their dynamic response. In Stadia, Arenas and Grandstands; CRC Press: Boca Raton, FL, USA, 1998; pp. 123-134.

30. Littler, J. Retractable Grandstands: Dynamic Response; BRE Watford: Watford, UK, 2000.

31. Setareh, M. Vibration serviceability of a building floor structure. I: Dynamic testing and computer modeling. J. Perform. Constr. Facil. 2010, 24, 497-507. [CrossRef]

32. Middleton, C.; Pavic, A. The dynamic stiffening effects of non-structural partitions in building floors. In Topics in Dynamics of Civil Structures; Springer: Berlin/Heidelberg, Germany, 2013; Volume 4, pp. 513-519.

33. Devin, A.; Fanning, P.; Pavic, A. Nonstructural partitions and floor vibration serviceability. J. Archit. Eng. 2016, 22, 04015008. [CrossRef]

34. Andersen, L.V.; Frier, C.; Pedersen, L.; Persson, P. Influence of furniture on the modal properties of wooden floors. In Model Validation and Uncertainty Quantification; Springer: Berlin/Heidelberg, Germany, 2020; Volume 3, pp. 197-204.

35. Falati, S. The Contribution of Non-Structrual Components to the Overall Dynamic Behaviour of Concrete Floor Slabs. Ph.D. Thesis, Oxford University, Oxford, UK, 1999.

36. Ruggieri, S.; Porco, F.; Uva, G. A practical approach for estimating the floor deformability in existing RC buildings: Evaluation of the effects in the structural response and seismic fragility. Bull. Earthq. Eng. 2020, 18, 2083-2113. [CrossRef]

37. Ruggieri, S.; Porco, F.; Uva, G. A numerical procedure for modeling the floor deformability in seismic analysis of existing RC buildings. J. Build. Eng. 2018, 19, 273-284. [CrossRef]

38. GB 50010-2010. Code for Design of Concrete Structures. 2015. Available online: http://www.mohurd.gov.cn/wjfb/201511/t201 51119_225665.html (accessed on 29 June 2021).

39. GB 50011-2010. Code for Seismic Design of Buildings. 2011. Available online: http://www.mohurd.gov.cn/wjfb/201608/t20160 801_228378.html (accessed on 29 June 2021).

40. GB/T 50081-2019. Standard for Test Methods of Concrete Physical and Mechanical Properties. 2019. Available online: http: / / www.mohurd.gov.cn/wjfb/201910/t20191012_242198.html (accessed on 29 June 2021).

41. Miao, Z.; Lu, X.; Jiang, J.; Ye, L. Nonlinear FE model for RC shear walls based on multi-layer shell element and microplane constitutive model. In Proceedings of the Computational Methods in Engineering and Science, EPMESC X, Sanya, China, 21-23 August 2006. 